\title{
FUENTES PARA EL ESTUDIO DEL ÓRGANO HISTÓRICO DE LA PARROQUIA DE SANTA INÉS ZACATELCO (TLAXCALA, MÉXICO)
}

\author{
SOURCES FOR THE STUDY OF THE HISTORIC ORGAN OF THE PARISH \\ OF SANTA INES IN ZACATELCO (TLAXCALA, MEXICO)
}

\author{
Gustavo Mauleón Rodríguez \\ gmauleon3@yahoo.es \\ ORCID iD: https://orcid.org/0000-0003-4308-7014 \\ Edward Charles Pepe \\ Seminario de Estudio de Órganos Históricos CNCPC-ENCRyM/INAH \\ ed@edpepeorgansofmexico.com \\ ORCID iD: https://orcid.org/0000-0003-4583-0385
}

\begin{abstract}
Resumen
En esta colaboración presentamos los resultados de un trabajo de investigación y documentación acerca de uno de los órganos mexicanos más importantes en varios sentidos, que fueron construidos durante la primera mitad del siglo XIX, siendo destinado a una parroquia del obispado de Puebla-Tlaxcala. Su constructor fue uno de los miembros más tempranos y notables de la familia de organeros Castro de la ciudad de Puebla de los Ángeles, se trata de Seferino Agustín Castro, a quien le tocó vivir la transición de la Nueva España hacia el México Independiente, siendo heredero una larga tradición local en la fabricación de órganos mecánicos de tipo español o ibérico, ahora diseñados bajo nuevas circunstancias históricas, musicales y tecnológicas, de las que son claros ejemplos sus instrumentos, mismos que, en lo particular, muestran también aspectos de la evolución del órgano poblano, con interesantes características propias.
\end{abstract}

\section{Palabras clave}

Seferino Agustín Castro; organero; organería; órgano español o ibérico; Puebla-Tlaxcala; Zacatelco.

\section{ALGUNOS ANTECEDENTES HISTÓRICOS}

La antigua iglesia de Zacatelco estuvo sujeta, como doctrina regular, a la administración del antiguo convento franciscano de Tepeyanco (ambos pueblos de la jurisdicción de Tlaxcala), hasta los inicios de la década de 1640, cuando fueron erigidas las parroquias de San Francisco Tepeyanco y Santa Inés Zacatelco, como parte de la nueva y contundente

\begin{abstract}
In this collaboration, we present the results of an investigation into and documentation of a Mexican organ that from several viewpoints can be considered one of the most important in the country. Constructed during the first half of the 19th century for a parish church in the Puebla-Tlaxcala diocese, this relatively large organ is the work of Seferino Agustin Castro an early member of one of the most notable families of organ builders, the Castros, who were based in Puebla de los Ángeles but whose work -much of which survives- also extended significantly into Tlaxcala. Seferino's life spanned the transition from the Viceroyalty of New Spain to independent Mexico and the organs, while clear products of a long tradition of mechanical-action organs of Spanish/Iberian design, simultaneously reflect new historic, musical, and technological circumstances. Moreover, they display characteristics that can be considered to be uniquely Pueblan and thus mark an important moment in the development of organs in that region.
\end{abstract}

\section{Keywords}

Seferino Agustin Castro; organ builder; organ building; Spanish organ; Iberian organ; Puebla-Tlaxcala; Zacatelco.

etapa en la secularización de las doctrinas, emprendida en la diócesis de Puebla-Tlaxcala por el obispo -hoy beato- don Juan de Palafox y Mendoza (1639-1654) ${ }^{1}$. Estos dos cura-

1 Para determinados casos y procesos de los siglos XVI y XVII acerca de la secularización de las doctrinas en la Nueva España, nos limitamos a mencionar a ARMAS MEDINA (1952): 101-129, PIHO 
tos, una vez secularizados, separados y delimitados, tuvieron como primeros párrocos al licenciado Juan de Sandoval y al bachiller Tadeo Guerrero, sin embargo, sabemos que, para 1642, el cura beneficiado de Zacatelco aún residía en Tepeyanco, asunto que el obispo Palafox atendió mediante algunas "diligencias"

En el ámbito del culto divino de la iglesia de Zacatelco, podemos comentar algunos antecedentes históricos relacionados particularmente con la actividad musical. De esta manera, se sabe que la antigua iglesia de este pueblo, a finales del siglo XVI, requería de una campana y algunos instrumentos musicales para su ajuar eclesiástico, los más antiguos de los que se tiene noticia en esa región. En efecto, en 1588, el campanero Alonso García y su mujer legítima, María Gutiérrez, se encontraban realizando algunos trabajos para esta iglesia, habiendo recibido para realizar la fundición de una campana pequeña de cinco quintales $(230.04 \mathrm{~kg})$ y la fabricación de ocho trompetas, la cantidad de 223 pesos por parte de los indios de la iglesia de Santa Inés "sujeta a Topoyango" (sic, por Tepeyanco), bajo una "cédula" firmada por un tal "fray Ambrosio", seguramente un franciscano doctrinero dependiente del convento de Tepeyanco que les habría ayudado a contratar la fabricación de los instrumentos.

Debido a ciertos incumplimientos por parte de los fundidores, los representantes de Zacatelco solicitaron a las autoridades apresar a Alonso García en la cárcel pública. No obstante, se le llegó a otorgar un nuevo plazo al taller, obligándose a los responsables a terminar con prontitud la campana y todas las trompetas, para lo cual "empeñaron" o dieron en prenda a una "india chichimeca" que, con toda seguridad, era esclava; garantizando así la entrega de los instrumentos una vez transcurrido el término de dos meses ${ }^{3}$.

(1977): 81-88, PIHO (1981), MORALES (1993): 465-495, y RUBIAL (1998): 239-272. Nuevos estudios y enfoques en PÉREZ PUENTE (2010), MAZÍN (2010): 139-211, MENEGUS (2010): 77-137, y MORALES (2010): 13-75.

2 Biblioteca Nacional de España (BNE), Ms. Visitas eclesiásticas de D. Juan de Palafox y Mendoza, obispo de la Puebla de los Ángeles, en su obispado, Mss/4476, f. 48v. Existen ediciones modernas comentadas: PALAFOX Y MENDOZA (2014 [y 1997]). Ver Archivo de la Fiscalía de Santa Inés Zacatelco (AFSIZ), caja 1, exp. 33 (año 1642).

3 Archivo General de Notarías del Estado de Puebla (AGNEP), Notaría núm. 4 (Escribano: Melchor de Molina), protocolo de 06.10.1588, f. 934r. El mismo Alonso García, como oficial de latonero, el año anterior de 1587 había otorgado un concierto para fabricar "seis trompetas bastardas para Navidad", destinadas al convento de San Agustín de la ciudad de Puebla de los Ángeles. AGNEP, Notaría núm. 3 (Escribano: Marcos Rodríguez), Protocolos de 1587, f. 1515r. Por la temporalidad, es posible que del mismo taller de latonería y fundición hayan procedido también otras trompetas que se enviaron a Guatemala desde Puebla en 1595, como parte de un flete muy variado de mercaderías: AGNEP, Notaría núm. 4 (Escribano: Baltasar de Montoya), Protocolos de 1595, f. 218 r. Este tema está siendo investigado para un estudio futuro.
La compra de estos juegos de trompetas puede tener varias lecturas. Es posible que la primitiva capilla de doctrina de Zacatelco, cuyo pueblo no era cabecera, no contara todavía con órgano tubular para el servicio del culto; por otra parte, resulta muy factible también que, desde tiempo atrás, se hubiesen arraigado entre los ministriles indios algunas prácticas musicales que se intentaron "moderar" desde el Primer Concilio Provincial Mexicano, como se verá.

Ya en el siglo XVII, poco después de creado el curato diocesano, el obispo Palafox, como hemos apuntado, llegó a poner especial atención en el asunto del párroco del beneficio creado en Zacatelco (1642). Asimismo, sus testimonios e impresiones de esta iglesia, durante la segunda visita episcopal (junio-agosto de 1643), quedaron escritos en su "Manual de la Segunda Visita Eclesiástica":

el día siguiente, 21 [de julio de 1644] después de oído misa salí a Santa Inés [f. 48v] de Topoiango que lo dividí en dos curas que son el licenciado don Juan de Sandoval, hombre docto y eminente en lengua mexicana, y el bachiller Thadeo Guerrero que asiste en la parroquia que está en el mesmo pueblo de Topoiango, ésta era doctrina de frailes franciscos, recién quitada, allí me recibió don Juan de Sandoval, di la bendición episcopal; hay muy buena iglesia en este partido ${ }^{4}$.

La nueva parroquia de Santa Inés, que -según testimonio del propio obispo- también tenía a "muchos españoles" labradores entre su feligresía, no podía ser la excepción en el cumplimiento irrestricto de las providencias diocesanas. Como sabemos, habiendo reconocido personalmente el estado y condiciones reales de buena parte de su obispado, Palafox emitió, en 1646, una serie de edictos fundamentales en la nueva configuración de la diócesis que respondían a las visitas eclesiásticas ya realizadas por este incansable prelado $(1643,1644,1646)$, orientados, en este caso, no sólo a una administración y comunicación parroquial más eficaz, sino también a mejorar y aumentar el exorno y ajuar eclesiásticos (en muchos aspectos, como es sabido, de acuerdo al manual de San Carlos Borromeo, Instructiones fabricae et supellectilis ecclesiasticae, 1577$)^{5}$, así como a la necesidad de dignificación, decoro y magnifiencia del culto conforme a las disposiciones y ordenamientos de la liturgia tridentina.

4 BNE, Ms. "Visitas eclesiásticas de D. Juan de Palafox y Mendoza, obispo de la Puebla de los Ángeles, en su obispado", Mss/4476, ff. 48r-48v. Para todas las versiones paleográficas hemos desatado las abreviaturas y normalizado dobles consonantes, puntuación y acentuación. 5 Existe edición castellana moderna: BORROMEO (1985). 
En este documento se ocupó particularmente de varios asuntos como "la división y forma de las cordilleras y prefecturas del obispado para enviar y recibir las cartas y despachos de oficio por las secretarías de gobierno y de justicia", así como en emitir nuevas disposiciones sobre "los ornamentos y vasos sagrados, y las demás alhajas y instrumentos que son necesarios para las parroquias y lucimiento del Culto Divino". Asimismo, para el seguimiento y control de estas últimas, ordenó que se le hicieran llegar memoriales con informaciones sobre lo existente en las iglesias de las cordilleras no visitadas aún, y sobre "las alhajas que han aumentado" en los partidos ya visitados -tal era el caso de las parroquias de Tlaxcala-, prometiendo además promociones y hasta prebendas eclesiásticas a los beneficiados que fueren calificando según las mejoras realizadas en sus curatos $^{6}$.

Efectivamente, entre las disposiciones se encontraban varios edictos referentes a libros litúrgicos, catequéticos y devocionales, manuales de lenguas indígenas e instrumentos musicales, siendo muy claro en insistir, de manera especial, en que:

si faltaren libros de canto para los indios, nos avisen para que se impriman o copien. Y asimismo los [libros de] Artes y Vocabularios de lenguas y Sermonarios, para que se los demos de nuestra secretaría, donde se ha recogido por nuestra orden de la[s lenguas] Mexicana, Totonaca, Chocha, Misteca y Otomí, para que entre tanto que se imprimen, si no los tuvieren impresos, ni manoescriptos, puedan trasladarlos y valerse dellos (PALAFOX Y MENDOZA, 1646,f. 7r).

En cuanto a la música, cabe mencionar que también fueron realizadas, en diferentes épocas, copias manuscritas con traducciones a lenguas indígenas de algunos impresos litúrgicos con canto llano, y otros de instrucción teórico-musical, de los que han sobrevivido, en Tlaxcala y en la Mixteca, algunos ejemplares aún desconocidos por la literatura musicológica. En el parágrafo noveno con el encabezado "De los libros e instrumentos de música de las parroquias", Palafox (1646) realiza unas ordenanzas con breves pero valiosos comentarios, que consideramos trascendentes para una mejor

6 Cabe comentar que en estos edictos aparece el orden de las cordilleras y los trece partidos con sus respectivas cabeceras y divisiones, iniciando con la de "Tlaxcala primera cabecera, que comprende a Topoyango, Santa Ynés [Zacatelco], Santa Ana Chautempa, San Juan, San Phelipe Gueyotlipa, Atliguetza, Tlaxcalaque, Atlangatepeque, San Miguel del monte" (PALAFOX Y MENDOZA, 1646, f. 1v, 7r-7v). De estos edictos hay edición moderna con comentarios por FERNÁNDEZ GRACIA (2000): 201-212, 340-352. organización de las prácticas musicales para el culto de las parroquias poblano-tlaxcaltecas:

Consérvense y guárdense los libros de la iglesias con todo cuidado, y donde no los hubiere se vayan comprando, y estos son los siguientes.

[f. 17v] Dos Misales, o por lo menos uno para el coro.

Un Breviario para las liciones, en caso de que los libros no las tengan.

Un libro del Psalterio.

Otro Dominical.

Otro Ferial.

Otro Cuaresmal.

Otro de Difuntos.

Otro común de festividades comunes.

Otro de festividades solemnes, y procuren tener éste por lo menos duplicado.

Procuren conservar mucho los instrumentos de canto, de que hay tanta copia en las parroquias de estas provincias, y el principal dellos, que es el órgano; y que vayan aprendiendo los indios, porque nunca falte quien lo sepa tocar.

Los instrumentos siguientes, si no los pudieren tener duplicados, los tengan sencillos.

Un órgano, y se procure mucho, que no haya parroquia sin él.

Una harpa.

Un juego de flautillas.

Otro de chirimías.

Un baxón.

Una corneta.

Un juego de trompetas, de las cuales se use fuera de la iglesia, a sus puertas, antes y después de la Misa, y de los oficios Divinos.

$\mathrm{Y}$ adviértase que al tiempo que se dice la misa mayor, cuando se canta alguna chanzoneta, particularmente después de haber alçado al Señor, han de usar de los instrumentos más suaves y que perturben menos, como son órgano, harpa y flautillas, porque antes despierten [f. 18r] atención al misterio, que ruido y perturbación; y [que] las trompetas nunca se tañan dentro de la iglesia.

Si bien el obispo es contundente en sus determinaciones acerca de los instrumentos musicales, particularmente del uso adecuado de las trompetas, resulta claro que, como en otros casos, llegó a tomar en cuenta lo dispuesto por los Concilios Mexicanos y otros documentos del siglo XVI, lo que puede poner en evidencia que ciertas costumbres, prácticas y necesidades musicales seguían presentes entre los indios de su obispado, siendo necesario por ello volver a insistir en su atención y control casi un siglo después. Recordemos que ya desde el Primer Concilio Provincial (1555) 
se había prescrito "que se modere la música e instrumentos" por el exceso que había de "chirimías, vigüelas de arco y trompetas", así como de "cantores, e indios que se ocupan en los tañer", por lo cual se dispuso "que de hoy más no se tañan trompetas en los Divinos Oficios, ni se compren más de las que se han comprado, las quales solamente servirán en la Procesiones que se hacen fuera de las Iglesias, y no en otro Oficio Eclesiástico", haciendo hincapié -dentro de ese contexto- en la necesidad de que hubiese un órgano en cada pueblo para que "cesen los estruendos y estrépitos de los otros instrumentos" (Concilios Provinciales, 1769, capítulo LXVI, pp. 140-141).

Volviendo a los edictos palafoxianos, vemos que desde el primer parágrafo, "De los templos, capillas, retablos y sus altares", ya se advierte acerca de la necesidad de dotar a los altares de campanas de mano y campanil: "tres campanillas, una para cada altar, y la del mayor sea un poco más grande, si no tiene rueda de campanillas", lo que se complementa, ya en el aspecto arquitectónico, en el décimo que trata "De los cementerios, visitas y campana", donde se indica que debe haber en cada iglesia "un campanario para las campanas, que esté cubierto y con algún género de adorno, como torreçilla o otro de esta calidad. Y [que] tengan por lo menos tres campanas, las mayores que se pueda" (PALAFOX Y MENDOZA, 1646 , ff. 9v, 18r).

De esta manera, resulta usual encontrar en los archivos parroquiales o de las fiscalías, diversos registros con pagos para la música del culto: organistas, ministriles, cantores, y hasta para el concurso de capillas musicales enteras, otros para "aderezos", renovaciones o compra de diferentes instrumentos musicales de la iglesia, etcétera. En Zacatelco se conservan, por ejemplo, algunas memorias o cuentas de diversos gastos realizados en diferentes fiestas y conmemoraciones especiales, así como en otros rubros de la fábrica espiritual o material; en ocasiones, inclusive se llega a avisar, mediante términos administrativos en náhuatl y nahuatlizados, las partidas de los bienes de donde podían provenir las cantidades a devengar: ylhuitomin, misatomin, metomin, trigotomin, tlaoltomin, patlahuactlaollitomin ${ }^{7}$. Entre las fiestas destacan la patronal de Santa Inés Virgen y Mártir, advocación tutelar fundacional; la del "Santísimo Sacramento" (Corpus Christi); la del "Santísimo Patriarca" (San José), y la de San Mi-

7 Entre otros, tenemos un ejemplo muy completo en un expediente sobre gastos del retablo, fiestas y otras obras de la iglesia, pagados de algunos de los bienes administrados: metomin (dinero de los magueyes); trigotomin (dinero del trigo); ylhuitomin (dinero de la fiesta); misatomin (dinero de las misas); tlaoltomin (dinero del maíz); patlahuactlaolli [tomin] (dinero del maíz ancho): AFSIZ, caja 3, exp. 158 (1730-1745), 3 fojas (Traducción de Luis Reyes García, 1997). guel Arcángel, en registros documentales generados por la administración de la fiscalía india a partir de 1694.

Sin embargo, muy poco sabemos acerca de los músicos locales o foráneos que desarrollaron actividades de manera permanente o esporádica en la parroquia de Zacatelco, capillas de sus barrios u otras sufragáneas en los pueblos sujetos y haciendas de dicho partido. Los datos de archivo resultan escasos, no obstante, existen documentos de tipo tributario, y entre ellos algunos padrones de barrios antiguos de Zacatelco (Ayletitlan, Zacatlamicmiloltitlan, Yzquitlan, Cuauhzinco), destacando dos interesantes listados con los nombres de los músicos, de sus cónyuges, en algunos casos también de sus hijos y su edad, así como el monto de la contribución; se trata de los "Cantores de Ayletitlan" y los "Cantores de Quauhzinco".

También se conserva otro testimonio en un expediente judicial (con declaratorias, autos, etc.) levantado entre los meses de marzo y abril de 1777 , por el que sabemos que el cantor de la parroquia de Santa Inés, en esa época, era un indio de nombre Joseph Mariano Marziales. En este caso se trataba de un "cantor" o maestro principal, ya que es el único músico mencionado entre los cargos y oficiales de la iglesia, por lo que seguramente también era organista. El documento es un ejemplo más del caso tan común en tiempos novohispanos, en que, por un lado, los ganados de vecinos españoles invaden y arruinan los sembradíos y sementeras de los indios por "accidente" o "descuido", y por otro, los indios se ven en la necesidad de arrendar sus tierras a personas no avecindadas en sus pueblos, en este caso a cierta casta de "coyotes mulatos".

$\mathrm{El}$ asunto es que unos comerciantes y arrieros españoles fueron objeto de "varios agravios de todos los oficiales del dicho pueblo y de Pedro el sacristán, Juan Bernardino, Josef Roque y Josef Mariano el cantor", consistentes en que, molestos principalmente por las constantes invasiones a sus tierras, los indios negaron a los españoles y sus familias la entrada a la iglesia parroquial durante la Semana Santa de 1777, tratando de evitar que recibieran el jubileo decretado para ese año, así como el sacramento de la Eucaristía, lo cual resultó muy escandaloso. Tras la queja formal ante los alcaldes de justicia de Tlaxcala y las averiguaciones correspondientes, finalmente se dictaron autos logrando conciliar a españoles e indios, quienes alcanzaron acuerdos comunes. Sin embargo, apenas transcurridos algunos días, los comerciantes y arrieros señalados volvieron a reincidir en sus malas prácticas ${ }^{9}$.

8 AFSIZ, Traslado parcial del "Padrón general y matrícula de tributarios desta Provincia [de Tlaxcala]", caja 3, exp. 189 (14.04.1758), ff. [18]v-[20]v; [26]v-[28]r.

9 AFSIZ, "Delixencias que siguen los naturales y españoles del pueblo de Santa Ynés Zacatelco desta jurisdisión [sic]", caja 3, exp. 202 (31.03.1777-19.04.1777), 14 fojas. 


\section{LOS ÓRGANOS DE PARROQUIA}

Como señala el obispo don Juan de Palafox, en sus edictos de 1646, era un asunto de importancia que las parroquias de su enorme diócesis fueran contando con órganos tubulares, y que pronto se enseñara a los indios a tañerlos para que siempre hubiese organistas disponibles durante las funciones divinas, especialmente en las celebraciones dominicales, fiestas de guardar y fiestas locales. El primer órgano del que tenemos noticias documentales, instalado en el primitivo edificio de la parroquia de Santa Inés Zacatelco, fue construido en 1650 por el organero Diego Sebaldos, siendo entonces afinador de los órganos de la catedral de Puebla, de manera informal, pero seguramente ya con un taller montado $\mathrm{y}$ funcionando en esa ciudad sede del obispado.

Sabemos que un primer protocolo de obligación, sin especificaciones técnicas o detalles constructivos, fue suscrito en diciembre de dicho año ante el escribano público Nicolás López Gallegos (de la cuarta notaría de la ciudad de Puebla), los otorgantes eran:

unos indios que mediante Diego de Gardea, intérprete del juzgado, dijeron llamarse Juan Cuautli, alguacil mayor del pueblo de Santa Inés Çacatelco, don Martín Baltazar Cuautli, fiscal, Francisco Sánchez, merino, Joseph Lorenzo, tequitlato, Pablo Martín, Francisco Hernández, tequitlato, y Diego Pérez, principales y mandones del dicho pueblo de Santa Inés, y dixeron que viendo la necesidad que padecía la iglesia de dicho pueblo de hórgano para su lustre, por no tenerlo hicieron diligencia de comprarlo, y con efecto Diego Sebaldos, maestro de hórganos, les vendió uno ${ }^{10}$.

El costo del instrumento fue de 1300 pesos, dando los representantes del pueblo e iglesia un significativo adelanto de 320 pesos. El resto fue pagado a plazos y en pequeñas cantidades durante poco más de 19 años. En el archivo de la parroquia de Santa Inés -como parte del mismo expediente- se resguardan los recibos que corren de 1651 a $1658^{11}$, y en el archivo de los fiscales se hallan otros recibos complementarios de 1659 a $1666^{12}$. No obstante, la suma de las cantidades a la vista en dichos recibos no alcanza a cubrir el monto total acordado con el organero. En efecto, sabemos

10 Archivo Histórico de la Parroquia de Santa Inés Zacatelco, Tlaxcala (AHPSIZ), caja 81 (olim 80), leg. 1, exp. 1 (01.12.165006.09.1658), ff. [1]r-[3]r.

11 AHPSIZ, caja 81 (olim 80), leg. 1, exp. 1 (01.12.165006.09.1658), ff. [3]r-[4]v.

12 AFSIZ, caja 2, exp. 45, (23.10.1659-09.05.1666), 1 foja. Confróntese GASTELLOU, y MAULEÓN (1999): 186. que en noviembre de 1669 aún no se había liquidado totalmente la deuda, ya que el maestro Sebaldos declaró en una de sus cláusulas testamentarias "que los naturales del pueblo de Santa Inés Topoiango [sic] me son deudores de cuarenta pesos de oro común, de resto de un mil y trescientos en que les vendí un órgano, ordeno se cobren por mis bienes" ${ }^{13}$.

En comparación con otros proyectos constructivos del mismo organero (a saber, los órganos para las catedrales de México y Puebla, así como otros órganos pequeños para el pueblo de Jonotla y para el convento de Nuestra Señora del Carmen de Puebla, estos últimos de seis y cinco mixturas respectivamente), el costo del de Santa Inés Zacatelco y lo poco que sabemos de la organería de este maestro, nos indican que pudo tratarse de un órgano de proporciones relativamente medianas, mismo que pudo ocupar un lugar definitivo dentro del nuevo templo parroquial, en cualquiera de las dos tribunas laterales construidas exprofeso, cuyas ménsulas de cantera basáltica, que sirvieron de soporte a las estructuras, aún se pueden apreciar a la altura del coro principal, desde la nave de la iglesia ${ }^{14}$. Este órgano sin duda representa también uno de los primeros instrumentos de que haya noticia, fabricados por Diego Sebaldos en el reino de la Nueva España.

Dada la notoriedad que cobró durante su breve florecimiento novohispano, bien merece la pena recordar que este maestro fue un inmigrante europeo originario de Praga, en el entonces reino de Bohemia; ya era vecino de Puebla a finales de la década de 1640, ciudad donde contrajo matrimonio en torno a 1650 con Josefa Martínez. Sebaldos tuvo a su cuidado los órganos de la catedral de Puebla, sin un salario fijo, entre 1649 (año de la consagración de la catedral por el obispo Palafox) y 1655; algunos indicios apuntan a poder vincularlo a un pequeño círculo de artistas europeos allegados a dicho obispo. Desde 1654 se encontraba realizando algunos "aderezos" y ampliaciones a un órgano grande que al parecer no estaba del todo acabado, terminándolo en 1655 (¿acaso se trataría del órgano que se ordenó comprar en 1648 para la nueva catedral? ¿Sería quizá también obra del propio Sebaldos?). Fue contratado formalmente como "templador" o afinador de los órganos de la catedral de Puebla en diciembre 1655 (con 50 pesos anuales, conservando la plaza hasta su muerte), posteriormente realizó otras reparaciones al “ór-

13 AGNEP, Notaría núm. 4 (Escribano: Nicolás Álvarez), Protocolos de testamentos, 05.11.1669, f. 216v.

14 El edificio reconstruido, siendo consagrado, al parecer comenzó a utilizarse a principios de la década de 1690, no obstante existen referencias en 1682 sobre el "aumento al culto divino y compostura de la iglesia", particularmente acerca de la construcción de la torre, ya que "su hermosa fábrica está careciendo della para su mayor lusimiento de que Dios Nuestro Señor se servirá”: AHPSIZ, caja 81 (olim 80), leg. 1, exp. 3 (19.04.1682), f. s/n. 
gano pequeño" o realejo (1656 y 1663), y de nueva cuenta al órgano grande (1663).

Como se sabe, fabricó un órgano para la catedral de México (1655-1656) por 2800 pesos, éste era de seis varas de alto, y quizá pudo haber tenido hasta diez "mixturas partidas" (registros partidos), lo que en realidad no queda muy claro por la descripción documental con que se cuenta. En 1660 ofreció a la catedral de Puebla un órgano ya construido que constaba, según una primera fuente documental, de "once mixturas sonorosas" y seis varas de alto por tres de ancho en 2000 pesos, mismo que no fue aceptado por el cabildo. Sin embargo, el órgano había quedado armado ya en algún lugar del edificio. Después de la muerte del organero (acaecida en noviembre de 1669), el instrumento -aún sin pertenecer a la catedral- se hizo colocar inmediatamente en la tribuna del lado de la Epístola (donde al parecer permaneció hasta 1707). Al final, después de un largo proceso burocrático, en 1678 el cabildo eclesiástico hizo tasar el órgano y procedió a firmar ante notario público una obligación para pagar a su hijo y heredero Lorenzo Sebaldos, un monto de sólo 1500 pesos, pagadero a tres plazos ${ }^{15}$.

Por ahora desconocemos más referencias al órgano en funciones o a la utilización de otros órganos en Zacatelco durante el resto de la época virreinal. Es hasta la segunda década del México independiente cuando se verifica la contratación de la fábrica de uno nuevo, siendo el único órgano que se conserva físicamente en dicha iglesia hasta la actualidad. De manera afortunada, en los archivos de la parroquia y de la fiscalía de Santa Inés se preservan varios expedientes sobre este caso, se trata de un órgano que se instaló en 1837, fabricado por el notable y productivo taller de Seferino Agustín Castro, organero activo durante poco más de la primera mitad del siglo XIX ${ }^{16}$, quien desarrolló su trabajo principalmente en las regiones de Puebla-Tlaxcala y la Mixteca. Como es sabido, este maestro fue miembro de una importante familia poblana de constructores de órganos tubulares ${ }^{17}$.

15 Se prepara un nuevo estudio sobre Diego Sebaldos en la Nueva España, mismo que incluirá una documentación amplia sobre su florecimiento novohispano. Algunos datos pioneros sobre Sebaldos y su órgano para la catedral de Puebla se encuentran en CASTRO MORALES (1983): 26. Para el caso del órgano de la catedral de México, ver el estudio de PEPE (2007a): 49-74.

16 ACEVEDO, MAULEÓN, y PEPE (2015).

17 Cabe mencionar que un familiar suyo, el también prolífico organero José Luciano Castro, fue requerido como afinador de los órganos de la catedral de Puebla, con un sueldo de tres pesos mensuales por la afinación de cualquiera de los tres órganos existentes, estando "obligado a las composturas y afinamientos ligeros de una y otra pieza que pudiera desconcertarse"; ello después de una importante "compostura" al "órgano grande" de la catedral (1808), llevada a cabo por el presbíte-
El maestro Seferino Agustín Castro, acompañado de su hijo José de la Cruz Castro, otorgó en la ciudad de Puebla, el 14 de febrero de 1837, un "instrumento y obligación", suscrito en hoja de sello de 1836-1837 (pero no ante notario público), a instancias del presbítero Pedro Pablo Vázquez (entonces capellán de erección, músico y cantor de voz tiple, así como rector del colegio de infantes de la catedral de Puebla $)^{18}$, a quien habría de entregarse un órgano terminado "a toda satisfacción" como perito y mediador ante "el pueblo y cabecera de Santa Inés Zacatelco", en cuya iglesia parroquial finalmente debería de quedar "parado y muy bien acondicionado" el instrumento, en un plazo de seis meses. En este breve contrato se especifica el costo inicial, que fue de 2000 pesos, así como sus proporciones generales: "un órgano mayor del tamaño de siete varas y media de largo, y cuatro varas de ancho, con su fondo correspondiente", un teclado manual de cincuenta y cuatro teclas (do3 a fa7) y "tres fuelles de marca". Por tratarse de un órgano con registros partidos de tipo español, en la lista de "mixturas" se anotan catorce medios registros de mano izquierda y catorce de mano derecha, más dos "juguetes", uno accionado del lado izquierdo del teclado y el otro del lado derecho, advirtiendo que todos los registros "serán de buena contextura y sonido" por lo que quedarían a satisfacción del presbítero Pedro Pablo Vázquez o de cualquier otro experto. Entre las condiciones de la entrega pide que los contratantes se obliguen a cubrir los gastos que sean generados por la provisión de materiales y el pago de los operarios del taller. Al final firma también su hijo, José de la Cruz Castro, como aval de la obligación de la obra ${ }^{19}$.

En el mismo expediente se fueron asentando durante varios meses los recibos que corresponden a los pagos realizados al organero por parte de la fiscalía de la iglesia de Zacatelco, representada por José Luciano Grande Morales, fiscal en turno. El primero de ellos, emitido al día siguiente de la firma del protocolo de obligación (15 de febrero de 1837), fue el pago más grande, de 492 pesos (aunque en el informe de las cuentas del órgano se anotó la cantidad de 490.4 pesos), al que le siguieron otros doce pagos con sus

ro Cayetano Carvallo, con el reconocimiento o dictamen de dicha obra y la afinación a cargo del organista José María Carrasco (Archivo del Venerable Cabildo de la Catedral de Puebla (AVCCP), AC 55, f. 235r. (10.06.1808)).

18 Sobre la actividad del presbítero y músico Pedro Pablo Vázquez en la catedral de Puebla: AVCCP, $A C$ 60, f. 79v (21.06.1822). AC 62 , f. $108 \mathrm{v}(18.12 .1827)$. AC 63 , f. $153 \mathrm{v}(10.12 .1830)$. AC 66, ff. 70r-76r (18.07.1843). AC 67, f. 52r (25.01.1848); f. 69v (04.08.1848); f. 150v (15.01.1849); ff. 208r-209v (15.10.1850); f. 241r (20.03.1851). AC 68, f. $143 \mathrm{r}(01.06 .1858) ;$ f. $158 \mathrm{v}(06.08 .1858)$.

19 AHPSIZ, caja 81 (olim 80), leg. 1, exp. 2 (09.02.183630.12.1837), f. [6]r-[6]v. Ver apéndice documental núm. 1. 
respectivos recibos, finiquitando el monto total nueve meses después (27 de noviembre del mismo año). Solamente dos de los recibos, los correspondientes a los días 7 y 14 de septiembre, fueron firmados en Zacatelco, debido a que en el pueblo se encontraba el maestro Castro para concluir y entregar el instrumento, y los demás en la ciudad de Puebla. En uno de los casos el emisario encargado de llevar el pago a esa ciudad fue el maestro vidriero José María Cardoso, quien realizó también, ese mismo año, algunas obras en la iglesia de Santa Inés ${ }^{20}$.

Según los detallados registros de la fiscalía, así como el informe sobre las cuentas del órgano que el fiscal rindió al párroco don Luis Gonzaga Gutiérrez del Corral ${ }^{21}$, el organero recibió en total la suma de 2001.1 pesos, de los cuales fueron pagados, de los bienes administrados por la fiscalía, 641.4 pesos, y la cantidad restante con que "contribuyeron los hijos del pueblo, puramente indígenas" fue de 1359.5 pesos. En dichos expedientes se fueron sumando otras cantidades menores por conceptos administrativos relacionados con gestiones, licencias y pago de derechos para la compraventa del instrumento, así como otros gastos de manutención de los trabajadores durante la instalación del órgano por la cantidad de $195.4{ }^{7 / 8}$ pesos "por 45 días mantenidos el maestro organero y sus oficiales". En cuanto a la decoración de algunos de los tubos, resulta singular que consten el cargo y el recibo por 27 pesos "de la obra de las flautas del órgano que se pintaron y doraron", pagados en 20 de agosto de 1837 por el fiscal José Luciano Grande y otro principal, Juan Flores, a un maestro dorador de la ciudad de Puebla contratado para ello ${ }^{22}$.

En el archivo de los fiscales se conserva también otro expediente que guarda relación al contener valiosas informaciones -algunas a confrontar con los datos ya comentados- sobre la obra del órgano, solemnidades de su estreno y dedicación, así como de otros gastos diversos, algunos de

20 AHPSIZ, caja 81 (olim 80), leg. 1, exp. 2 (09.02.183630.12.1837), f. [6]v-[9]r.

21 En 1841, el presbítero Luis Gonzaga Gutiérrez del Corral ya era "segundo cura" de la parroquia del sagrario de la catedral de Puebla; poco después párroco de la misma y catedrático de legua griega en el Seminario Palafoxiano. Fue autor de sermones, panegíricos y traductor de alguna obra de doctrina moral escrita en lengua italiana. Falleció el 22 de marzo de 1848, siendo canónigo penitenciario. En Actas Capitulares también se registran otras noticias referentes a su actividad en dicha catedral: AVCCP, AC 65, f. 140v (14.03.1840); f. 208r (25.06.1841). $A C$ 67, f. 13v (17.03.1847); f. 59r (23.03.1848); f. 178v (24.05.1850).

22 AHPSIZ, caja 81 (olim 80), leg. 1, exp. 2 (09.02.1836$30.12 .1837)$, f. [1]r-[4]r. Un traslado con algunas variantes de la primera parte del informe de la fiscalía a la parroquia sobre las obras del órgano y vidrieras en AFSIZ, caja 5, exp. 300 (15.02.1837-30.12.1837), 2 fojas $s / n$. ellos relativos al culto, de manera directa o indirecta. Se trata de un documento de "cuenta y descargo" (cargo y data), llevado minuciosamente por la propia fiscalía en turno para la administración general de todo el año 1837. Aunque presenta ciertas diferencias con el informe y recibos mencionados, en esta cuenta aparecen los pagos que se fueron haciendo al organero poblano, anotando además algunas cuestiones internas, por ejemplo, que el mencionado maestro vidriero José María Cardoso llegó a financiar a la fiscalía en dos ocasiones "porque ya no tiene alcances el pueblo", y quizá por la misma razón, otro de los pagos al organero se tuvo que devengar "en dos partidas" 23 .

De igual manera, por este expediente se sabe que ciertas obras de carpintería y ensamblado de los componentes del instrumento comenzaron a finales de julio, ya que el taller envió a Zacatelco a "un carpintero y un tallador" que llegaron el día 30 de dicho mes y trabajaron en ese lugar hasta el 26 de agosto. Por su parte, el maestro Seferino Agustín Castro arribó personalmente a Zacatelco para el día 29 de agosto, junto con "el maestro músico don Ignacio Miranda y otro segundo maestro, un carpintero" ${ }^{24}$, quienes al parecer permanecieron poco más de dos semanas, tiempo en el que habrían supervisado los últimos detalles de la construcción y el armado, procediendo, como era habitual, a dar voz y afinar los tubos, así como a realizar las pruebas de rigor en el instrumento, mismo que fue acabado finalmente el día 14 de septiembre y fue entregado el día siguiente. Habiendo trascurridos ya siete meses desde la firma de la obligación, el día que dio término la obra se colocó en una parte interna del órgano (en la cara posterior de la reducción) una etiqueta manuscrita que dice: "Se acavó este Órgano día 14 de / Septiembre del año de 1837, siendo señor / Fiscal Don Luciano Grande Morales, / su autor Seferino Agustín Castro"25.

Un hecho nada común entre la documentación de los órganos históricos de México es que, tras la conclusión de la obra de este órgano, el dorador José Carlos Campos y un aprendiz suyo pudieron comenzar a trabajar in situ en

23 AFSIZ, caja 5, exp. 301 (01.01.1837-31.12.1837), f. [5]r. Ver apéndice documental núm. 2.

24 Ignacio Miranda también era conocido como organero, sabemos que en esta época colaboraba con la catedral de Puebla y con el taller del maestro Seferino Agustín Castro; naturalmente también estaría vinculado con el organista José María Carrasco. Un ejemplo de ello lo tenemos en 1834, cuando el cabildo catedralicio le dio a Ignacio Luchichi licencia para ausentarse por un mes, con el compromiso de que, para las fiestas solemnes de diciembre 8 y 12, debería entregar acabado el "órgano mayor", su solicitud iba acompañada con un informe del chantre y los certificados del organista José María Carrasco y del organero Ignacio Miranda: AVCCP, AC 64, f. 81v (19.09.1834).

25 Por error se transcribió el año de 1814 por " 1816 ", en GASTELLOU, y MAULEÓN (1999): 187. 
la decoración de los 43 tubos de la fachada (pertenecientes al registro Flautado Mayor 8'), ya que, como hemos visto, este maestro había cobrado por su trabajo y otorgado su recibo desde el 20 de agosto, fecha en la que ya debería haber estado lista la obra del órgano, según lo contratado, por lo que el dorador tuvo que esperar casi un mes para poder comenzar. Los trabajos de dibujo, pintura y dorado tuvieron una duración de tan sólo once días, plasmando en los tubos los tradicionales mascarones y motivos fitomorfos ya de gusto neoclásico, más un simbólico cordero (raíz latina de su nombre: Agnus/Agnes/Inés) con la palma del martirio (dentro de una corona de cuentas con la cruz), como atributos de la patrona Santa Inés Mártir, representados en el tubo mayor del castillo central ${ }^{26}$. Como hemos apuntado, a todos estos maestros y oficiales se les cubrió su manutención y, con seguridad, también el hospedaje durante sus estancias en Zacatelco, siendo "mantenidos todos con desayuno, almuerzo, comida, chocolate, sobretarde y la cena" 27 .

La función del domingo 8 de octubre de 1837 se dedicó a la patrona de la parroquia, santa Inés, por tratarse del día del estreno y bendición del órgano, y por ser una fiesta con calidad de solemne, se llevó a cabo, desde el día anterior, el oficio divino a vísperas y a maitines "de tres padres", continuando la agenda litúrgica con el oficio de tercia "de tres padres", misa "de tres padres" y procesión "de un padre", aplicándose para ello 20 pesos. A esta celebración asistieron, como invitados por la catedral de Puebla, desde luego, el presbítero Pedro Pablo Vázquez, como uno de los promotores; el maestro organista José María Carrasco “y dos más compañeros catedráticos [sic, por catedralicios], y otros fuera de ellos que asistieron en la orquesta", cuyos gastos y honorarios ascendieron a 153 pesos; es posible que, dado el monto del estipendio, la orquesta fuese muy nutrida y que durante el estreno haya tocado el órgano, en algún momento, el maestro Carrasco, tratándose de un organista que gozaba de suficiente renombre y era además buen conocedor del trabajo de los $\mathrm{Castro}^{28}$. Cabe mencionar que en dicha cuenta se

26 Uno de los trabajos pioneros en el estudio de este tema, lo ha llevado a cabo una profesora de la Escuela Nacional de Conservación, Restauración y Museografía "Manuel del Castillo Negrete" (ENCRYM / INAH), para defender la tesis de maestría en historia del arte: ALCÁNTARA BRAVO (2015-2017).

27 AFSIZ, caja 5, exp. 301 (01.01.1837-31.12.1837), f. [5]r.

28 José María Carrasco $(* 1781 ; \dagger 1845)$ : Primer organista de la catedral de Puebla a partir de 1799, maestro de canto de órgano y tecla de los niños infantes, y fungió como comisario durante las intervenciones a los órganos; en el AVCCP se conservan algunas obras suyas de tipo litúrgico (un motete y diez responsorios latinos). Sobre su actividad en dicha catedral: AVCCP, AC 52, f. 291r (19.02.1799). AC 53, f. 13v (10.05.1799); f. 10r (07.06.1799); ff. 116r-117v (15.07.1800); f. 195 r (14.08.1801). AC 55, f. 238r (27.05.1808); f. 235r (10.06.1808). registraron inclusive los "gastos de cocina" (que siempre se aplican en el documento por concepto de comida u "obsequio de cantores") por otros $164.2^{3 / 4}$ pesos "por la fiesta del estreno del órgano", cantidades no menores que reflejan la importancia religiosa y el significado musical de este acontecimiento ${ }^{29}$.

El maestro Victoriano Flores, organista de Puebla, fue el músico encargado de visitar la parroquia "desde que se principió la obra del órgano hasta que se acabó, desde a mediado de enero $[\mathrm{sic}]$ hasta octubre 8 , que se hizo la bendición", seguramente para supervisar las obras, hacer pruebas en el órgano y tocar en las funciones litúrgicas del estreno, cuyos emolumentos y gastos por traslados, durante esos meses, ascendieron a 50 pesos. Todavía el lunes 9 de octubre se aprovechó la presencia del maestro Flores para que hubiese acompañamiento de órgano, ya que en esa fecha se celebró de manera extraordinaria en la parroquia la fiesta del "Santísimo Patriarca" San José, la razón era que el día oficial de su fiesta (19 de marzo) había caído en domingo de Ramos ese año, y el único domingo disponible en el calendario para llevarla a cabo se había ocupado precisamente en las solemnidades por el estreno del órgano.

Un dato revelador es que la iglesia estaba falta de organista, lo que puede indicar que desde hacía un tiempo indeterminado ya no había un órgano en funciones, por ello "los principales del pueblo" determinaron que el maestro Victoriano Flores fuese el encargado a partir del 15 de octubre "hasta inter que haiga quien lo pueda tocar", ajustándose las cantidades de sus honorarios y de los gastos de sus viajes. En la cuenta de la fiscalía constan, además, registros minuciosos con todas las fechas en las que asistió el organista y sus pagos correspondientes durante el resto del año de 1837 , constituyendo las primeras funciones litúrgicas que fueron acompañadas por el nuevo órgano tubular ${ }^{30}$.

AC 58, f. 127r (16.12.1817); f. 128r (19.10.1817); f. 147r (17.02.1818); f. $148 \mathrm{r}(19.02 .1818)$. $A C 59$, f. $102 \mathrm{r}(16.03 .1820)$. $A C 60$, f. $252 \mathrm{v}$ (05.12.1823). AC 61, f. 119r (03.12.1824). AC 62, f. 108v (18.12.1827); f. $238 \mathrm{v}(19.12 .1828) . A C 63$, f. $154 \mathrm{v}(14.12 .1830)$. $A C 64$, f. $80 \mathrm{v}$ (19.09.1834); f. 81v (19.09.1834). AC 65, f. 108v (29.10.1839). AC 66, f. 158 r (26.09.1845); f. 159r (07.10.1845). Un resumen biográfico con datos sobre su etapa temprana en la catedral de Morelia (Valladolid), Michoacán, algunas obras musicales y tratados, así como otras fuentes bibliográficas en PAREYÓN (2006): 189.

29 AFSIZ, caja 5, exp. 301 (01.01.1837-31.12.1837), f. [2]r, [3] $\mathrm{r},[3] \mathrm{v}$.

$\mathrm{r},[5] \mathrm{v}$. 


\section{DOCUMENTANDO EL ÓRGANO HISTÓRICO DE ZACATELCO}

Invitados en febrero de 2015 por el grupo Comunicación, Arte y Cultura (FCC/BUAP), que se encontraba desarrollando una misión de investigación interdisciplinaria en la parroquia y comunidad de Santa Inés, municipio de Zacatelco, Tlaxcala, Gustavo Mauleón Rodríguez ofreció la conferencia "Santa Inés Zacatelco, aspectos musicales de una parroquia novohispana", como parte de un ciclo titulado: Patrimonio y memoria. El retablo de Zacatelco, actividades que, de manera académica, discurrieron en torno la culminación de la restauración del retablo mayor de Santa Inés en la iglesia parroquial de Zacatelco.

Poco después comenzamos a trabajar conjuntamente en una nueva documentación del órgano tubular histórico de Zacatelco, en la que contamos con la valiosa colaboración del organero José Luis Acevedo Guzmán, durante junio y noviembre del mismo año, también con miras a realizar un estudio más general enfocado a la organería del maestro Seferino Agustín Castro. Los trabajos de esta etapa se cerraron con un concierto en el órgano histórico, ofrecido por Edward C. Pepe (el sábado 12 de septiembre de 2015), mismo que fue promovido por la parroquia, la fiscalía, el comité local para la restauración del retablo de Santa Inés y el propio grupo de investigación Comunicación, Arte y Cultura (FCC/BUAP) ${ }^{31}$.

Los datos conocidos, las informaciones obtenidas en nuevas pesquisas documentales y otras observaciones, nos permiten presentar provisionalmente una cronología general de los principales momentos en la historia del órgano de Zacatelco:

I. Se otorga el contrato de obligación el 14 de febrero de1837.

II. Se concluye el órgano siete meses después -y no seis como indica el contrato-, colocándose una etiqueta alusiva al término de las obras con fecha de 14 de septiembre de 1837.

III. En algún momento, que desconocemos, se hacen adherir las etiquetas de los registros que vemos.

31 Desafortunadamente, el órgano histórico de Zacatelco no ha recibido un mantenimiento constante y tampoco un tratamiento profesional supervisado por el Centro INAH-Tlaxcala y por la Coordinación Nacional de Conservación del Patrimonio Cultual del INAH (que ahora cuenta con un Equipo de Conservación de Órganos Históricos en el Área de Conservación de Patrimonio Histórico in situ). Por otra parte, el Instituto Tlaxcalteca de Cultura (ITC) también organiza conciertos con motivo de un festival de órganos históricos promovido por dicha dependencia estatal con cierta regularidad, teniendo a Santa Inés Zacatelco como una de sus sedes, y logrando con sus programaciones una buena afluencia de públicos locales y visitantes.
Aunque éstas son antiguas, no se puede afirmar que sean originales, es decir, del maestro Castro. Por supuesto, existen dudas, dado que las etiquetas no corresponden por completo, ni con los registros que tiene el órgano en la actualidad, ni con el contrato.

IV. En la cara interna de uno de los paneles de la fachada se adhirió otra etiqueta manuscrita por la que consta que el órgano tuvo una "compostura" terminada el 28 de diciembre de 1912 por el organero Antonio B. Rangel $^{32}$.

V. Según una inscripción en el costado derecho de la caja, el órgano "fue reformado" en $1944^{33}$.

VI. El órgano sufrió, en tiempos más recientes, por lo menos dos intervenciones: 1983-1984 y 1997-1998. Sobre ello contamos con un testimonio personal, y según el Catálogo de órganos tubulares históricos de Tlaxcala, el instrumento se encontraba en proceso de restauración en 1998 por Joaquín Wesslowski ${ }^{34}$, sin embargo, los detalles aún son escasos.

Revisando la literatura, se puede ver que el órgano aparece ya en el libro pionero de John Fesperman, Organs In Mexico (1980), pero en él solamente da un número total de registros, que según ese estudio eran 32, es decir, 32 medios registros. En ese momento se decía que se trataba de un órgano bastante completo, pero que no servía porque el sistema de aire no funcionaba ${ }^{35}$. Por su parte, el inventario Voces del arte (1989) (de la entonces SEDUE) consigna una disposición según las etiquetas y se menciona que el órgano estaba en buenas condiciones pero que no servía. Asimismo, se informa que para el año 1989 aún no había sido instalado un motor para los fuelles. Cabe recordar que la información que se encuentra en dicho inventario fue proporcionada por Susan Tattershall ${ }^{36}$. Por su parte, el Catálogo de órganos tubulares históricos de Tlaxcala (1999) también da la disposición de los registros según las etiquetas, sólo que la ficha levantada no está del todo completa ya que faltan dos registros de la mano derecha. Menciona ese estudio que para 1998-1999 se conservaba $70 \%$ de los componentes origina-

32 Etiqueta manuscrita: "Con fecha 28 de Diciembre de 1912, el or- / ganero, Señor Don Antonio B. Rangel termi- / nó la compostura de este Órgano; siendo / Encargado de la Parroquia el Señor Presbítero Don / Guadalupe Clemente y Cruz; y Fiscal / el Señor Don Pedro Juárez".

33 "Este órgano fue reformado por los / mayordomos de la santa patrona del año de / 1944 / Sección 1 a / Maximiano Roxas y / Rafael Sánchez / Sección 2a / Epigmenio Álvarez y / Cándido Romero / Sección 4 / Juan Garzón y / Rafael Hernández”.

34 GASTELLOU, y MAULEÓN (1999): 170.

35 FESPERMAN (1980): 82.

36 Voces del Arte (1989): 164-165. 
les del instrumento, y que había un ataque significativo de termitas $^{37}$.

Conocemos, por testimonio del doctor Sabino Yano Bretón (entonces director del ITC), que el instrumento tuvo una restauración que él mismo gestionó, a cargo de la mencionada Susan Tattersall ("hacia 1983-1984"), intervención que no se menciona en Voces del Arte y de la que no se conocen más detalles ${ }^{38}$. Asimismo, el asunto de la restauración más reciente (1997-1998) también resulta muy enigmático. Por desgracia, parece que hay muy poca documentación disponible (algunas fotografías de 1998 propiedad del actual organista José Orlando Hernández, en que se aprecian algunas vistas del órgano durante la restauración e imágenes de una visita de la licenciada Verónica Rascón, entonces presidenta del DIF estatal, quien al parecer también ayudó en la gestión de recursos públicos. Del órgano existen también otras fotografías de este momento en el acervo privado del antropólogo Luis Martín Martínez ${ }^{39}$, pero no se sabe nada sobre el estado del instrumento antes de la intervención, ni sobre el trabajo realizado. Sin embargo, queda bastante claro que la restauración resultaba complicada.

De hecho, el maestro José Orlando Hernández, que ya era organista en ese momento, comenta que Tattershall empezó a trabajar -de nueva cuenta-desde 1997 (en sociedad con José Miguel Quintana en la parte administrativa), y no se les permitió retirar de la parroquia tubos y componentes del órgano como era su intención. Ese año dio inicio el nuevo proyecto que contó con un apoyo tripartita bajo las gestiones del maestro Roberto Pérez Ortiz del ITC, con el apoyo de: Conaculta, el Gobierno del Estado de Tlaxcala y la comunidad de Zacatelco a través de la Parroquia. No obstante, en febrero de 1998, los trabajos ya estaban a cargo del maestro organero Joaquín Wesslowski (el Catálogo de órganos tubulares históricos de Tlaxcala también menciona que en septiembre del mismo año la restauración se encontraba avanzada y faltaban "por terminar la Corneta clara, Corneta de ecos, Lleno (lado derecho) y los juguetes"). El órgano se reinauguró el 14 de diciembre del mismo año (siendo párroco de Zacatelco el padre Adrián Gutiérrez, fiscal el señor Juan Arenas Romano y organista José Orlando Hernández, quienes, junto con la Comisión Diocesana de Arte Sacro de Tlaxcala, tuvieron también un papel importante en la gestión de esta obra $)^{40}$.

37 GASTELLOU, y MAULEÓN (1999): 170.

38 Comunicación personal (marzo de 2016).

39 Comunicación personal (junio de 2015). El maestro Hernández nos permitió gentilmente hacer reprografías a sus impresiones fotográficas.

40 Comunicación personal (noviembre de 2015).
Edward C. Pepe visitó el órgano en 2005, con el maestro Wesslowski y un grupo de estudiantes de la Escuela de Música Sacra de la Universidad de Yale. Durante esa visita el maestro Wesslowski proporcionó a los asistentes algo de información del órgano en una hoja descriptiva, en cuyo texto él mismo se presentaba como el restaurador del órgano. Curiosamente, en esa hoja se copia la disposición del órgano también según las etiquetas, sin embargo, como ya se mencionó, la disposición actual no corresponde completamente con las mismas. Además, salta a la vista que la hoja también presenta una datación del órgano como "c. 1800".

Con el órgano de Santa Inés Zacatelco vemos que la documentación no siempre ofrece soluciones, sino que a veces ocasiona más dudas. En este caso existe el contrato, la confirmación de la entrega y el órgano actual, pero el problema es que los datos no siempre coinciden. Claro que no es sorprendente que un órgano llegue hasta nosotros en una forma no original, pero en este caso se ven inconsistencias desde el principio. Lo que es quizá más sorprendente es que las etiquetas no coinciden con la descripción del órgano que aparece en el contrato, ni con el órgano que existe hoy en día. Este asunto recuerda que en muchos casos un órgano no siempre se construye exactamente como se especifica en el contrato, tal como pasó con el de Jorge de Sesma para la catedral de México; el órgano de Félix Yzaguirre para la catedral de Puebla, o el órgano de la Epístola de Joseph Nassarre, también para la catedral de México.

Por mencionar sólo algunos aspectos, en el contrato para el órgano de Zacatelco se anota una lista con los nombres de 14 registros en cada mano, más los de un juguete para cada lado, pero el órgano hoy día presenta 13 registros en la mano izquierda y 16 en la mano derecha, más un juguete accionado de cada lado. ¿De esta manera se construyó el órgano?, o ¿se cambió en algún momento posterior añadiendo o restando registros? Las etiquetas anuncian varios registros que no aparecen ni en el contrato ni en el actual órgano, como por ejemplo Corneta Magna y Espigueta en ambas manos. El contrato anuncia NASARdo MAYor y NASARDo Menor en la mano izquierda, así como NasArdo MaYor en mano derecha, pero no aparecen en las etiquetas actuales, aunque desde luego que pueden estar con otro nombre. El contrato incluye un registro de LLENo en la mano izquierda, pero no en la mano derecha; en contraste, las etiquetas anuncian LLENo en mano derecha pero no en mano izquierda, correspondiendo con la actualidad del órgano. El contrato incluye los registros de Quincena en ambas manos y ToLOSANA en la mano derecha, que no aparecen en las etiquetas; el registro de ToLOSANA sí se encuentra hoy en día pero al parecer las Quincenas no. El contrato incluye ConTRAs en ambas manos, pero las etiquetas dicen CONTRAS en mano izquierda 
y Flautado de 26 en mano derecha. El contrato coloca los juguetes Pájaros al lado izquierdo y Timbales al derecho, pero el órgano actual los presenta invertidos.

Queda claro que algunas de las inconsistencias que se presentan aquí tienen que ver con la terminología. Las etiquetas de la mano derecha presentan el FLAUTADO de 26 como Flautado Mayor y no como Contras. Asimismo, nombran Octava Mayor al Flautado de 8. Por ello será necesario averiguar exactamente qué registros hay en realidad en el órgano antes de solucionar el asunto. También será fundamental estudiar otros órganos de Seferino Agustín Castro de diferentes épocas y tamaños, por ejemplo: el de la Basílica de Ocotlán, el de San Luis Teolocholco, el de Santiago Tetla (de 1819, hasta ahora el órgano fechado y más antiguo que se conserva de este organero), entre muchos otros localizados también en Tlaxcala y en el vecino estado de Puebla, principalmente (aunque sabemos de otros instrumentos de los Castro en Morelos y Oaxaca). Varios de los órganos del maestro Seferino, desafortunadamente, ya han sido intervenidos en diferentes épocas, algunos dramáticamente y de manera no óptima, y lo que es peor, sin generarse o conservarse documentación con respeto al trabajo que se hizo en ellos.

En cuanto a la integridad física y actual estado de conservación del órgano, en somero reconocimiento, pudimos cerciorarnos que como parte del sistema de viento será necesario en un futuro revisar las fugas y conexiones, principalmente en el portavientos, y que el motor actual es totalmente inadecuado y hasta peligroso por el tipo de instalación eléctrica. En la parte del teclado se observa que las guías están en mal estado, las teclas tienen fricción entre sí, a lo que se suma que las varillas se encuentran desajustadas, así como la acción mecánica de los registros. Los secretos presentan ataque aparente por xilófagos, por lo que requiere de una revisión minuciosa y, en su momento, una fumigación especializada.

Por otro lado, muchos de los tubos presentan diversas deformaciones y se requiere revisar la posición de los registros en los tiples; los soportes y panderetes se encuentran vencidos o deformados y por ello los tubos han perdido sus posiciones normales. Asimismo, en los tubos de la fachada se observan serias deformaciones en sus pies; uno de los juguetes (PÁJAROS) no funciona; se observa también que algunas lengüetas no afinan correctamente. En lo que hace al mueble, éste presenta un serio deterioro por ataque de xilófagos y algunos vencimientos o deformaciones visibles y faltan algunos paneles de la parte posterior de la caja ${ }^{41}$.

41 ACEVEDO, MAULEÓN, y PEPE (2015).
En general, es evidente que el órgano necesita de una limpieza a fondo, ya que se han acumulado grandes cantidades de polvo y suciedad. Por otro lado, ante la urgencia de detener algunos de los deterioros mencionados, sugerimos al licenciado presbítero Elpidio Pérez Portilla, párroco de Santa Inés, y al señor Esteban Morales, fiscal de la iglesia durante 2015, solicitar a la Coordinación Nacional de Conservación del Patrimonio Cultural del Instituto Nacional de Antropología e Historia (INAH), comisionar a un equipo de especialistas para inspeccionar y realizar un registro detallado del bien mueble. Con una respuesta favorable por parte de dicha dependencia federal, la visita se pudo llevar a cabo el día 17 de noviembre de 2015, a cargo de las restauradoras Sandra Álvarez Jacinto y Norma Peña Peláez (del Equipo de Conservación de Órganos Históricos del Área de Conservación de Patrimonio Histórico in situ, CNCPC/INAH).

\section{CONCLUSIONES}

El órgano tubular que se conserva en la parroquia de Santa Inés Zacatelco, sin duda, se puede considerar entre los más importantes de México, debido su tamaño, su fecha relativamente temprana entre las obras de la familia Castro conocidas en el siglo XIX, algunos aspectos constructivos, su relativo buen estado de conservación y, desde luego, por la notable cantidad de documentación que se ha preservado acerca de muy variados aspectos de su historia.

En los trabajos preliminares de investigación y documentación recién cumplidos, nos hemos percatado de que en diferentes intervenciones -de las que hemos podido documentar al menos dos en la primera mitad del siglo $\mathrm{XX}_{-}$, ya no existía un entendimiento musical y tecnológico de la organería desarrollada por el maestro Seferino Agustín Castro y otros organeros integrantes de su familia, en gran medida aún sustentada en lo que conocemos como "órgano español" u "órgano ibérico". Sin embargo, resulta insoslayable preguntarnos acerca de la permanencia y alcances regionales de esa tradición, de las posibles variantes y novedades, así como de los nuevos usos y repertorios musicales para estos órganos, aspectos que requieren de estudios más serios y concienzudos. Acerca de las intervenciones más recientes, todavía quedan muchas cuestiones por indagar. Será necesario entonces emprender en un futuro una nueva etapa de investigación in situ sobre aspectos más organológicos (técnicos y constructivos), a partir de los componentes internos del órgano, toda vez que se cuente con la autorización y supervisión del INAH para intentar resolver por lo menos algunas las interrogantes que aquí hemos planteado.

En lo referente a su estado de conservación, el dictamen que resulte de la inspección y registro llevado a cabo por 
la CNCPC/INAH, deberá orientar las acciones inmediatas a tomar por parte de los responsables de la iglesia parroquial, seguramente con el apoyo del propio INAH, por tratarse de un bien mueble histórico de carácter federal. También esperamos que los documentos que se generen: dictamen, registro del órgano tubular (con la posibilidad de que éste pueda formar parte de un registro nacional), así como el informe de los trabajos preventivos que se lleven a cabo, puedan ponerse a consulta en los archivos de dicha dependencia gubernamental. Ojalá que el presente trabajo ayude a una mejor apreciación de este notable instrumento musical histórico, así como a tomar medidas apropiadas para la culminación de su restauración en un futuro y, desde luego, para su debida conservación.

\section{ANEXO DOCUMENTAL}

1. Informe de la fiscalía de Santa Inés Zacatelco a la parroquia sobre la compraventa e instalación del órgano TUBULAR, CON SU CONTRATO Y RECIBOS. SE INCLUYEN OTRAS CUENTAS Y RECIBOS SOBRE LAS VIDRIERAS DE LA IGLESIA (9 de febrerO de 1836-30 de diciembre de 1837)

Archivo Histórico de la Parroquia de Santa Inés Zacatelco, Tlaxcala. Caja 81 (olim 80), leg. 1, exp. 2 fojas $\mathrm{s} / \mathrm{n}$.

\section{[f. [1]r]}

[Margen superior, aviso manuscrito moderno: Compra del órgano 1837]

[Hoja de "SELLO CUARTO UNA CUARTILLA. PARA LOS AÑOS DE MIL OCHOCIENTOS TREINTA Y SEIS Y OCHOCIENTOS TREINTA Y SIETE"]

Santa Inés Zacatelco, febrero 15 de 1837.

A saber el cargo de la plata.

En 15 del dicho [mes y año] recibí el importe de la plata la cantidad de 842 pesos, 4 reales.

Descargo.

En 15 del mismo mes se le dio al maestro organero la cantidad de 490 pesos, 4 reales

0490,4

Ítem, 300 pesos que quedaron en depósito en casa de don José María Cardoso, y le cogió la moneda antigua en 14 de marzo de dicho año y quedaron libres 150 pesos

Ítem, 38 pesos, 2 reales, quedaron en poder de don José María Cardoso en su cuenta de las vidrieras

Ítem, 8 pesos de derechos que se le pagaron a señor licenciado [Serrano] promotor, consta por su recibo con fecha 9 de febrero [de 1836]

Y para que conste lo firmé:

[Fiscal] José Luciano Grande [firma y rúbrica]

\section{[f. [1]v en blanco]}

\section{[f. [2]r]}

Santa Inés Zacatelco, diciembre 30 de 1837

Yo el actual fiscal José Luciano Grande y mi república, le hacemos presente la cuenta al señor cura don Luis [Gonzaga] Gutiérrez [del] Corral: que han estado a mi cargo los bienes de la santa iglesia, y por lo que se originó en la obra del órgano, por el pagamento y gastos, y es la siguiente: 
Descargo

A saber

Primeramente se le tiene satisfecho al maestro organero don Seferino Castro, como consta en la escritura otorgada en 14 de febrero de 1837.

Son de la plata

El resto es de 1359 pesos, 5 reales, contribuyeron los hijos del pueblo, puramente indígenas, para el completo de 2001 pesos, 1 real de dicha obra, como consta en varias partidas de los recibos en la misma escritura con sus citadas fechas

En 20 de agosto de [1]837 se le pagó al maestro dorador de la obra de las flautas y pintura, como consta por su recibo con fecha del dicho [mes y año]

Reposición de las vidrieras $[\ldots]$

Y para que conste lo firmé:

José Luciano Grande [firma y rúbrica].

[f. [2]v en blanco]

[f. [3]r]

[Margen izquierdo: Son 8 pesos]

[Recibo:] Pagaron los vecinos de Santa Inés Zacatelco ocho pesos del pedimento en su solicitud para realizar la plata [sic] de aquella iglesia para comprar un órgano. Puebla febrero 9 de 1836.

Licenciado Serrano [firma y rúbrica].

$[\ldots]$

[f. [3]v en blanco]

[f. [4]r]

$[\ldots]$

[Margen izquierdo: Son 27 pesos].

[Recibo:] Recibí de los señores ofisales [sic, por oficiales] don Luciano Grade y el cuidano [sic, por ciudadano] Juan Flores la cantidad de 27 pesos de la obra de las flautas del órgano que se pintaron y doraron, y para que coste [sic, por conste] lo firmé a veinte de agosto de 1837.

José Carlos Campos [firma y rúbrica].

[f. [4]v en blanco]

$[\ldots]$

[f. [6]r]

[Hoja de "SELLO SEGUNDO DOCE REALES. PARA LOS AÑOS DE MIL OCHOCIENTOS TREINTA Y SEIS Y OCHOCIENTOS TREINTA Y SIETE”]

[Obligación de la obra]. En la ciudad de los Ángeles, a los catorce días del mes de febrero de mil ochocientos treinta y siete, yo el ciudadano Seferino Agustín Castro, maestro organista, me comprometo en toda forma de derecho a hacer un órgano mayor del tamaño de siete varas y media de largo, y cuatro varas de ancho, con su fondo correspondiente, cuyo teclado constará de cincuenta y cuatro teclas con sus tres fuelles de marca, y éste será entregado al presbítero don Pedro Vázquez, cuyo órgano 
es para el pueblo y cabecera de Santa Inés Zacatelco, en el precio de dos mil pesos, el que deberé entregar parado y muy bien acondicionado en dicho pueblo en el perentorio término de seis meses contados desde la fecha en que otorgo esta mi obligación, la cual a falta mía, cumplirán mis hijos, cuyo instrumento se compondrá de las mixturas siguientes:

$\begin{array}{ll}\text { Mano Izquierda } & \text { Mano Derecha } \\ \text { Flautado Mayor } & \text { Flautado Mayor } \\ \text { Flautado Bardón } & \text { Flautado Bardón } \\ \text { Contras } & \text { Contras } \\ \text { Octava Clara } & \text { Octava Clara } \\ \text { Nasardo Mayor } & \text { Nasardo Mayor } \\ \text { Nasardo Menor } & \text { Quinsena } \\ \text { Quinsena } & \text { Dozena } \\ \text { Dozena } & \text { Corneta Clara } \\ \text { Octava Parda } & \text { Corneta de Ecos } \\ \text { Decisetena } & \text { Tolozana } \\ \text { Decinovena } & \text { Deci[se]tena } \\ \text { Lleno } & \text { Flautado Dulce } \\ \text { Clarines } & \text { Dulsaina } \\ \text { Trompetas } & \text { Trompetas } \\ \text { Pájaro } & \text { Tambor }\end{array}$

Éstas serán de buena contextura y sonido que se entregarán a toda satisfacción del mencionado presbítero u otro cualquiera perito, al mismo tiempo queda el dicho pueblo en la obligación de ministrarme los reales que me fueren necesarios para el avío de materiales y pago de operarios, y el resto o alcan- [f. [6]v] ce se me entregará luego que dicho órgano quede entregado sin demora alguna, y en caso de que esto haya, se me supra pagarán los gastos que emprenda hasta quedar totalmente satisfecho y en fe de cumplir lo que llevo dicho, otorgo este instrumento y obligación, sujetándome en todo a las generales que del caso habla, renunciando todas las que sean en mi favor, sujetándome al arbitrio de los jueces que sobre mí tengan jurisdicción, y lo firmo en Puebla a 14 de febrero de 1837.

Seferino Agustín Castro [firma y rúbrica].

En defecto del señor mi padre:

José de la Cruz Castro [firma y rúbrica].

[Margen izquierdo: Son 492 pesos]

[Recibo:] Recibí de la república del pueblo de Santa Inés Zacatelco la cantidad de cuatrocientos noventa y dos pesos para avío del órgano que está expresa y lo firmo a 15 de febrero de [1]837.

Seferino Castro [firma y rúbrica].

[Margen izquierdo: Son 151 pesos]

[Recibo:] Recibí más ciento cincuenta y un pesos del señor fiscal y demás principales en 20 de marzo de [1]837.

Seferino Castro [firma y rúbrica].

[f. [7]r]

[Recibo:] En día $1^{\circ}$ de abril [de 1837] recibí 49 pesos, 4 reales del fiscal y demás señores principales.

Seferino Castro [firma y rúbrica].

[Recibo:] Recibí del señor fiscal y demás señores principales del pueblo de Santa Inés Zacatelco, la cantidad de ciento setenta y seis pesos en cuenta del órgano, y porque conste lo firmo en Puebla a 12 de abril de [1]837.

Seferino Castro [firma y rúbrica]. 
[Recibo:] Recibí del señor fiscal de Santa Inés Zacatelco, la cantidad de ciento dieciséis pesos, el día 20 de abril de [1]837, y porque conste lo firmo.

Seferino Castro [firma y rúbrica].

[Recibo:] Recibí del señor fiscal de Santa Inés Zacatelco la cantidad de doscientos diecinueve pesos, el día 7 de junio de [1]837, y porque conste lo firmo.

Seferino Castro [firma y rúbrica].

[Recibo:] Recibí del señor fiscal del pueblo de Santa Inés, don José Luciano Grande, la cantidad de ciento diecinueve pesos con cuatro reales, y porque conste lo firmo en Puebla a 13 de julio de [1]837.

Seferino Castro [firma y rúbrica].

[f. [7]v]

[Recibo:] Recibí del señor fiscal del pueblo de Santa Inés Zacatelco, ciento cincuenta y ocho pesos, y para que conste doy éste en 24 de agosto de [1]837 en Puebla.

Seferino Castro [firma y rúbrica].

[Recibo:] En 7 de septiembre [de 1837] recibí cien pesos en dos partidas, y para su constancia doy éste en el pueblo de Santa Inés Zacatelco.

Seferino Castro [firma y rúbrica].

[Recibo:] En 14 de septiembre de [1]837, recibí ciento noventa pesos, y [para] que conste doy éste en el pueblo de Zacatelco. Seferino Castro [firma y rúbrica].

[f. [8]r]

[Hoja de "SELLO CUARTO UNA CUARTILLA. PARA LOS AÑOS DE MIL OCHOCIENTOS TREINTA Y SEIS Y OCHOCIENTOS TREINTA Y SIETE"]

[Margen izquierdo: Son 100 pesos].

[Recibo:] Recibí del ciudadano José Luciano Grande, la cantidad de cien pesos que del pueblo de Santa Inés Zacatelco [que] me remite el señor fiscal, los cuales son en cuenta del resto del órgano que puse en dicho pueblo, y porque conste doy éste que lo firmo en Puebla a 5 de octubre de 1837 años.

Seferino Agustín Castro [firma y rúbrica].

[f. [8]v en blanco]

[f. [9]r]

[Hoja de "SELLO CUARTO UNA CUARTILLA. PARA LOS AÑOS DE MIL OCHOCIENTOS TREINTA Y SEIS Y OCHOCIENTOS TREINTA Y SIETE”]

[Margen izquierdo: Son 100 pesos].

[Recibo:] Recibí del señor José María Cardoso, la cantidad de cien pesos, del resto del órgano que se hizo para el pueblo de Santa Inés Zacatelco, y porque conste lo firmo en Puebla a 27 de noviembre de 1837.

Seferino Castro [firma y rúbrica].

[Margen izquierdo: Son 35 pesos].

[Recibo:] Recibí del señor fiscal del pueblo de Santa Inés Zacatelco don Luciano Grande, la cantidad de treinta y cinco pesos. Con lo que se cierra la cuenta del importe del órgano, y porque conste lo firmo en Puebla a 27 de noviembre de [1]837.

[Margen izquierdo: de la chapa 1 peso, 1 real].

Seferino Castro [firma y rúbrica]. 
[f. [9]v en blanco].

2. EXPEDIENTE CON LA “CUENTA Y DESCARGo" DE 1837 SOBRE DERECHOS PARROQUIALES, CERA, ACEITE, LAVAdO DE ROPA, HARINA, Carbón, incienso, pólvora, Cantores, cocina, cobros, Fletes, Peones, vigas, Carpinteros, herraje, Cal, ladrillo, ALBAÑILES, CUENTAS DEL ÓRGANO, VIDRIERAS, ORGANISTA, ETC. (1 de enero de 1837-31 de diciembre de 1837).

Archivo de la Fiscalía de Santa Inés Zacatelco, Tlaxcala. Caja 5, exp. 301 (año 1837), 6 fojas s/n.

[f. [1]r]

Cuenta y descargo desde el primero de enero, hasta el fin de diciembre de 1837.

Primeramente por el estipendio y derechos parroquiales que paga el pueblo.

$[\ldots]$

[f. [2]r]

En $1^{\circ}[\mathrm{de}]$ octubre. Dominica

En 8 [de] ídem [octubre]. Por la función que se le aplicó a la Santa Patrona

en este día por el estreno y bendición del órgano [fiesta en] que hubo

víspera y maitines de tres padres, tercia de tres padres, misa de tres

padres, procesión de un padre

En 9 [de] ídem. Dominica

En 15 [de] ídem. Dominica

4,0

En 22 [de] ídem. Dominica

4,0

En 29 [de] ídem. Dominica

4,0

$[\ldots]$

[Suma.] 36, 0

[f. [3]r]

Derechos de Cantores.

En 5 [de] febrero. Por la fiesta de Carnestolendas

13,4

En 24 [de] mayo. Por la del Corpus Cristi

En $1^{\circ}$ [de] junio. Por la Octava de Corpus

03,0

En 12 [de] julio. En los 8 días del novenario y la fiesta de la Preciosa Sangre de Cristo de Santo Toribio

[Xicohtzinco]; por la escasez de agua

En 28 [de] agosto. Por el recibimiento del señor obispo [don Francisco Pablo Vázquez], siendo [párroco el]

señor don Luis [Gonzaga] Gutiérrez [del] Corral

En 8 [de] octubre. Por el estreno del órgano que asistió [el] señor don Pedro Vázquez, don José María Carrasco, y dos más compañeros catedráticos, y otros fuera de ellos que asistieron en la orquesta; [fiesta en] que hubo maitines, tercia, y la función 153,0

Ídem, por la víspera del Santísimo Patriarca que se celebró en 9 de octubre; por el 19 de marzo que fue domingo de ramos

En 9 de ídem [octubre]. Por la fiesta del Santísimo Patriarca se pagó al que tocó el órgano don Victoriano

Flores

1,0

$[\ldots]$

[Suma.] 203, 4 [sic] 


\section{[f. [3]v] \\ [...]}

Gastos de Cocina.

En 5 de febrero. Por obsequio de cantores. En Carnestolendas

En 29 de mayo. Ídem [obsequio de cantores. En] Corpus Cristi

En 8 de octubre. Por la fiesta del estreno del órgano

\section{$[\ldots]$}

\section{[f. [5]r]}

Pagamento y gastos del órgano.

En 15 de febrero. El primer tercio, como comienza en la escritura que hemos ido abonando

En 20 [de] marzo

[En] $1^{\circ}$ [de] abril. Más

[En] 12 [de] ídem. Ítem

[En] 20 [de] ídem. Ítem

[En] 7 [de] junio de [1]837 esta cantidad nos franqueó el caballero don José María Cardoso

Porque ya no tiene alcances el pueblo, se le tiene abonado:

[En] 13 [de] julio. Ítem

[En] 24 [de] agosto. Ítem

[En] 7 [de] septiembre. Ítem. En dos partidas

[En] 15 [de] ídem. Ítem

[En] 5 [de] octubre

100,0

[En] 27 [de] noviembre. El caballero don José María Cardoso me franqueó 50 pesos para el complemento de 100 pesos

[Nota:] Para el complemento de 2000 pesos se restan 27 pesos.

[En] 20 [de] agosto se le pagó al maestro don Carlos Campos de la obra de las flautas. Por el dorado y pintura; consta por su recibo con fecha 20 [de agosto de 1837]

$\mathrm{Al}$ señor licenciado promotor. Se le pagó por la licencia de la plata, el cual recibo se ha extraviado; consta por los testigos don Alejo Hernández y don Juan de la Cruz Flores, y por mí el fiscal; pagamos

En 30 de julio vinieron dos maestros, un carpintero y un tallador, un aprendiz, hasta el 26 de agosto. Ídem, en 29 de agosto vino el maestro don Seferino Castro, el maestro músico don Ignacio Miranda y otro segundo maestro, un carpintero; y hasta el 15 de septiembre que entregó el órgano, un maestro dorador y un aprendiz que trabajaron 11 días, y fueron mantenidos todos con desayuno, almuerzo, comida, chocolate, sobretarde y la cena; y es el [monto de] todo 
[f. [5]v]

$[\ldots]$

En 15 de octubre a don Victoriano Flores se le hizo de cargo el órgano [para] que él lo toque, por los principales del pueblo, hasta inter que haiga [sic] quien lo pueda tocar; y el ajuste que hubo por sus viajes, los días domingos 2 pesos y los días 19, y demás entre semana que le toca el título, 12 reales menos por las andas [sic] en el mes. En 15 del dicho [mes]

[Otros pagos al organista].

En 13 de octubre. Por la vuelta del señor obispo de los llanos a Puebla, pasó su ilustrísimo [señor] de visita

En 19 de ídem. Ídem

En 29 de ídem. Ídem

1,4

En 30 de ídem. Por el frío, misa de salud del señor obispo

2,0

En 31 [de] ídem

1,0

1,0

$[\ldots]$

Suma. 9,0

[f. [6]r]

[Otros pagos al organista].

En $1^{\circ}$ de noviembre. En la misa primera se acabó la misa del frío [sic] para la salud del señor obispo, y en la segunda

En 12 [de] ídem. Ídem

2,0

En 19 [de] ídem. Ídem Dominica

2,0

En 26 [de] ídem. Ídem

2,0

Suma. 8,4

[Otros pagos al organista].

En $1^{\circ}$ [de] diciembre

En 17 [de] ídem. Adviento

2,0

En 19 [de] ídem

1,4

En 24 [de] ídem

2,0

En 25 [de] ídem

2,0

En 26 [de] ídem

1,0

En 27 [de] ídem

1,0

En 28 [de] ídem

1,0

En 31 [de] ídem

2,0

Suma. 13, 4

[...]

Por el gasto que se originó en las idas y venidas desde que se principió la obra del órgano hasta que se acabó, desde a mediado de enero hasta octubre 8 , [día en] que se hizo la bendición [del órgano]

$[\ldots]$ 


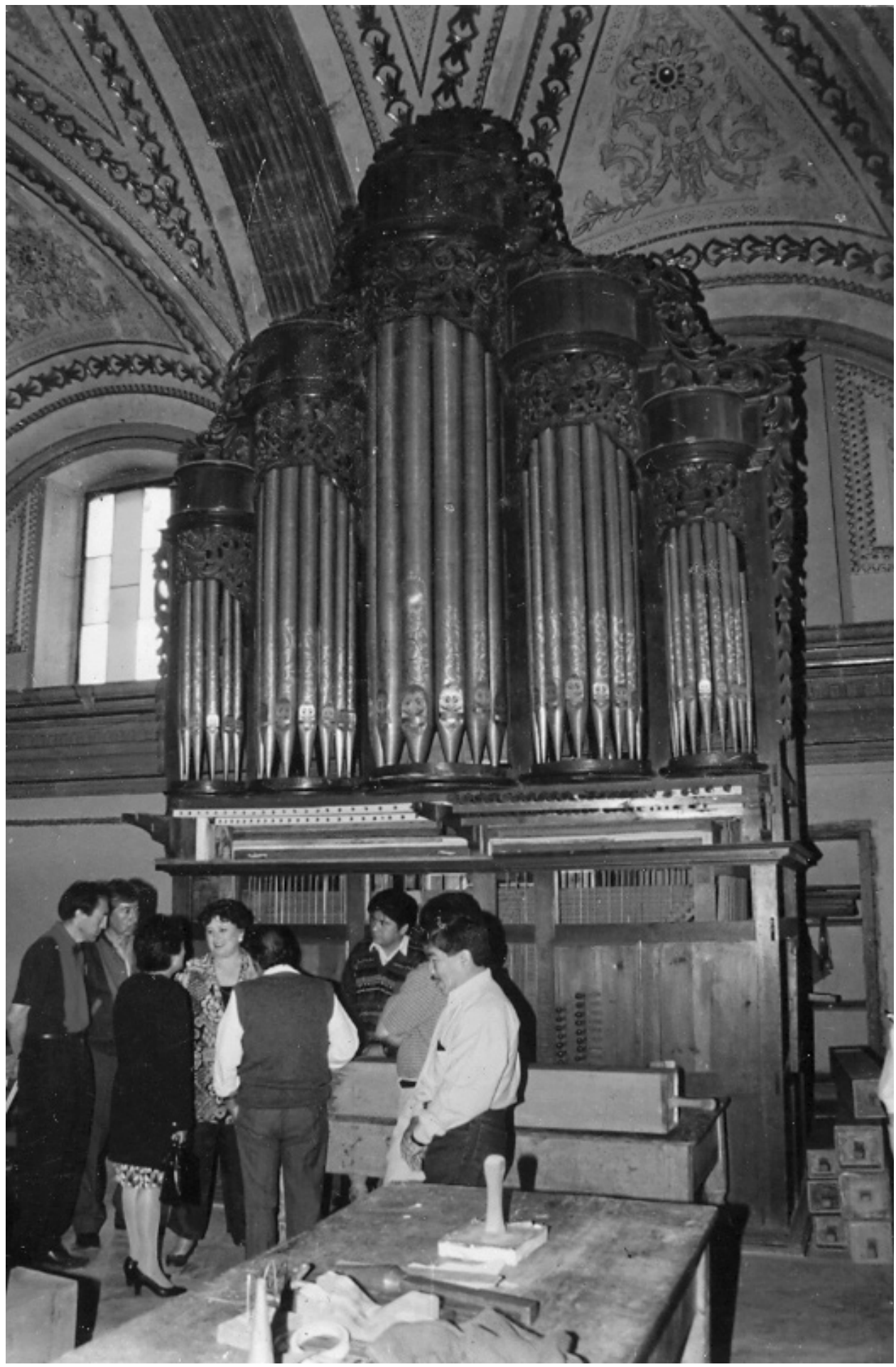

Fig. 1. Órgano histórico de Zacatelco durante la restauración de 1998 (visita de autoridades del DIF del Estado de Tlaxcala). [Fotografía: propiedad de José Orlando Hernández]. 


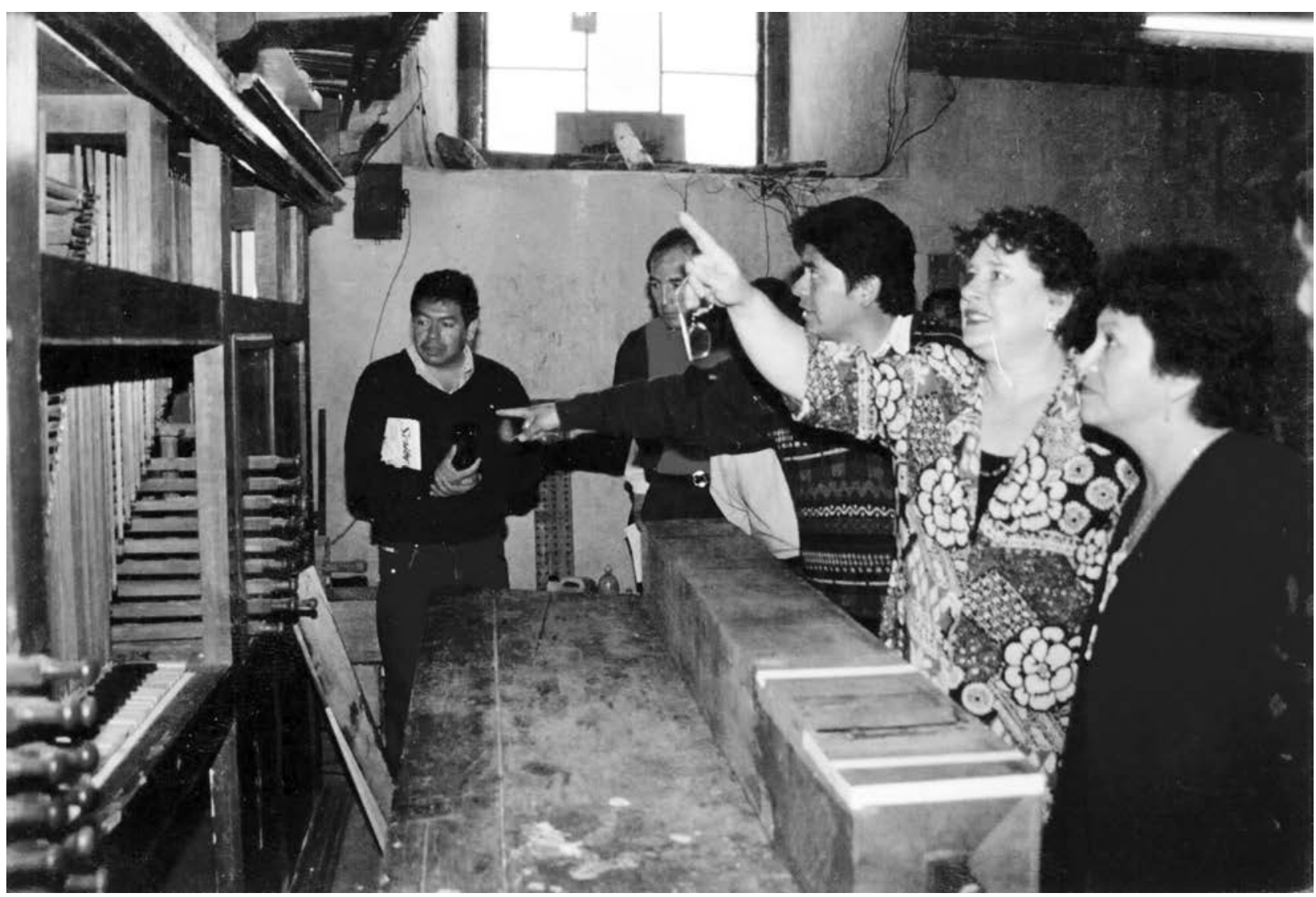

Fig. 2. Órgano histórico de Zacatelco durante la restauración de 1998. [Fotografía: propiedad de José Orlando Hernández]. 

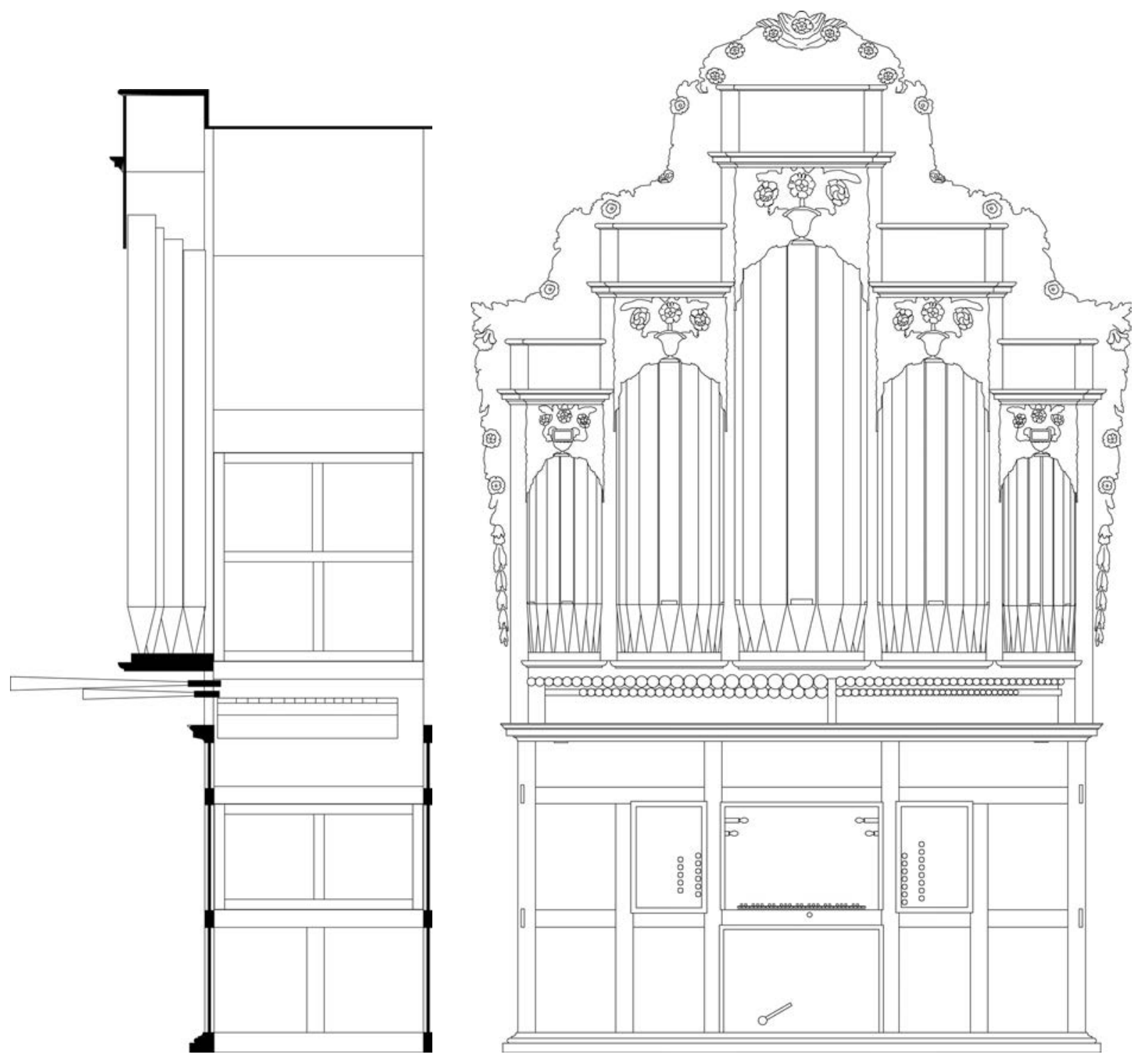

Fig. 3. Esquemas (sin escala) del órgano histórico de Santa Inés Zacatelco:

fachada, corte lateral y planta.

[Dibujo: José Luis Acevedo (2015)].

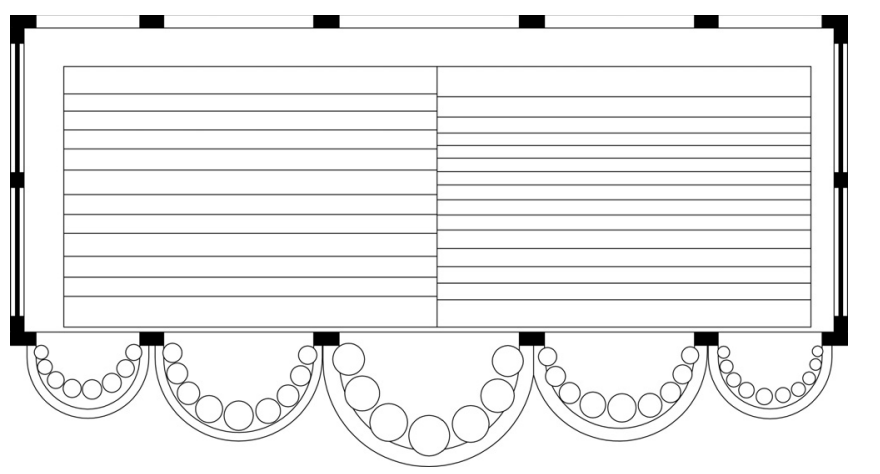




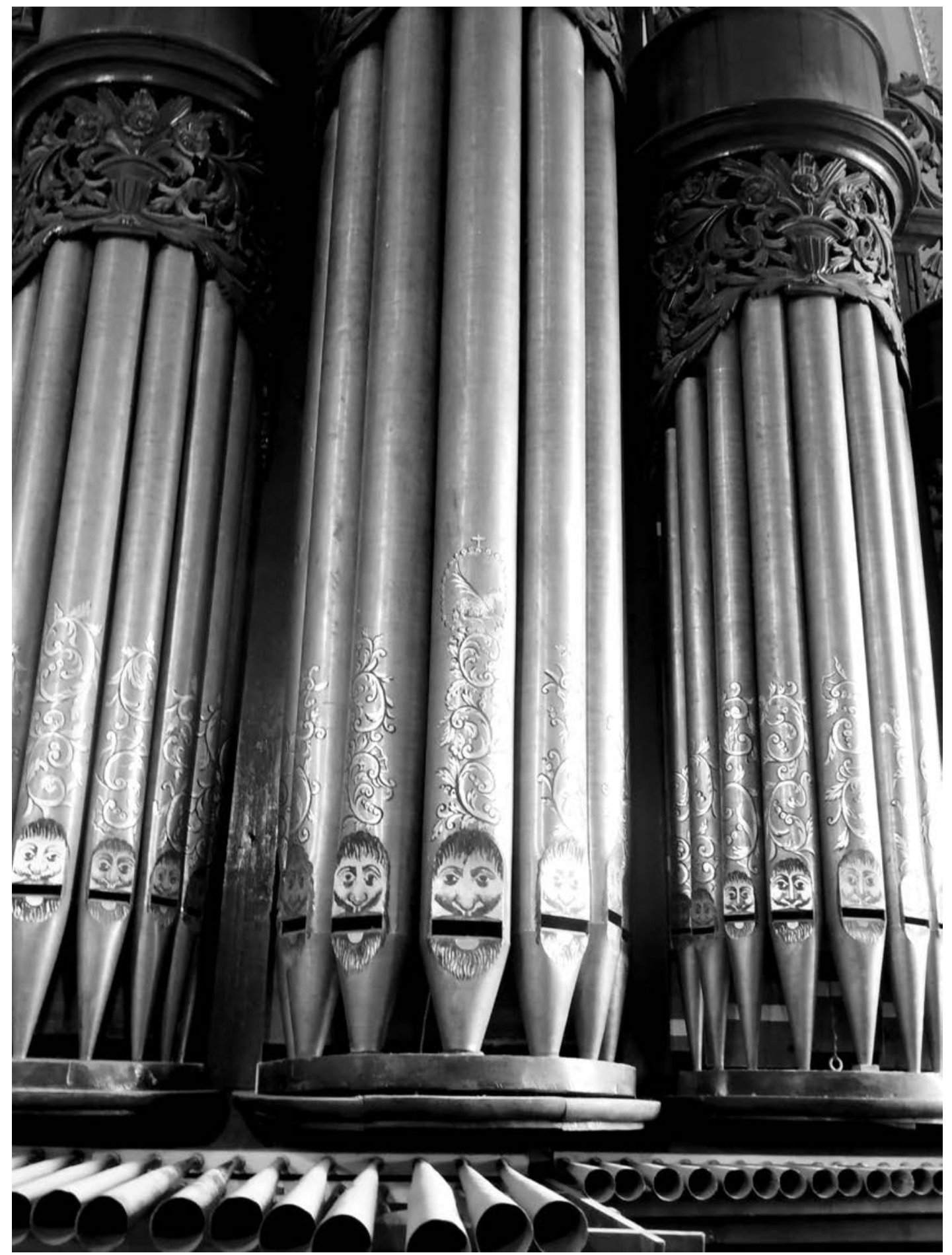

Fig. 4. Detalle de los tubos de la fachada del órgano histórico de Santa Inés Zacatelco.

[Fotografía: Gustavo Mauleón (2014)]. 


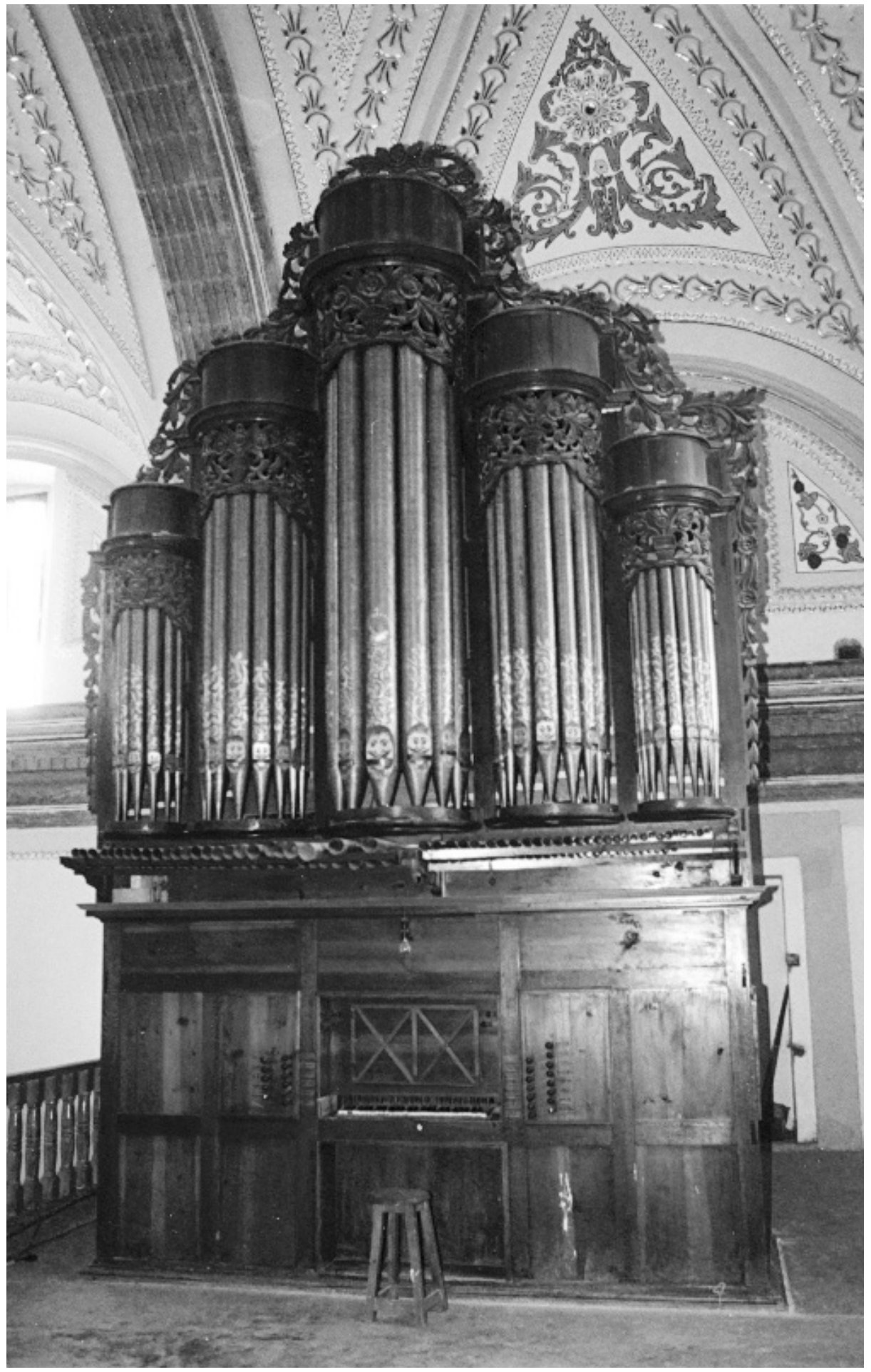

Fig. 5. Vista general de la fachada del órgano histórico de Santa Inés Zacatelco.

[Fotografía: Edward Pepe (2014)]. 


\section{BIBLIOGRAFÍA}

Acevedo, José Luis, Mauleón, Gustavo, y Pepe, Edward Charles: "Avances en la investigación sobre la organería de Seferino Agustín Castro (s. XIX)", III Coloquio de Conservación de Órganos Tubulares. México, INAH/CNCPC-ENCRYM, 2015 [Ponencia inédita].

Alcántara Bravo, Charlene: Los mascarones en los flautados mayores de tres órganos tubulares novohispanos de Oaxaca: Estudio iconográfico, iconológico y formal de San Andrés Zautla, San Jerónimo Tlacochahuaya y San Pedro Quiatoni. Tesis de maestría en Historia del Arte. México, Instituto Cultural Helénico, 2015-1017.

Armas Medina, Fernando de: "Evolución histórica de las doctrinas de indios", en Anuario de Estudios Americanos, IX, 1952, 101-129.

Borromeo, Carlos: Instrucciones de la fábrica y del ajuar eclesiásticos [1577]. Introducción, traducción y notas de Bulmaro Reyes Coria. Nota preliminar de Elena Isabel Estrada de Gerlero. México, UNAM, 1985, (Estudios y fuentes de arte en México 49).

Castro Morales, Efraín: "Los órganos de la Nueva España y sus artífices", en Efraín Castro Morales et al., Música y Ángeles. Los órganos de la catedral de México. México, Sociedad de Amigos del Centro Histórico de la Ciudad de México, 1983, pp. 21-37.

Castro Ramírez, Jesús Eduardo: "Palafox, Obispo de Puebla de los Ángeles: Pastor al servicio de las almas", en Ricardo Fernández Gracia (coord.), Palafox, Iglesia, Cultura y Estado en el siglo XVII. Congreso Internacional. IV Centenario del Nacimiento de Don Juan de Palafox y Mendoza, Pamplona, Universidad de Navarra, 2001, pp. 161-176.

Lorenzana, Francisco Antonio (ed.): Concilios Provinciales Primero y Segundo, celebrados en la Muy Noble y Muy Leal Ciudad de México, presidiendo el Illmo. y Rmo. Señor D. F. Alonso de Montufar, en los años de 1555 y 1565. México, Imprenta del Superior Gobierno de José Antonio de Hogal, 1769.

Cuadrupani Bernabita, Carlos José: Avisos que para tranquilizar en sus dudas a las almas tímidas escribió en italiano el M.R.P.D. Carlos José Cuadrupani, tradújolos de la edición 51 Luis Gutiérrez Corral Cura de la parroquial del Sagrario de la Santa Iglesia Catedral de la Puebla y catedrático de la lengua griega en el Seminario Palafoxiano de la misma, Tercera edición castellana. Puebla, Imprenta antigua en el portal de las flores, 1842 .

Fernández Gracia, Ricardo: Don Juan de Palafox Teoría y Promoción de las Artes. Pamplona, Asociación de
Amigos del Monasterio de Fitero, Ministerio de Educación, Cultura y Deporte, 2000.

Fesperman, John: Organs in Mexico. Raleigh, The Sunbury Press, 1980.

Gastellou Josué, y Mauleón, Gustavo: Catálogo de órganos tubulares históricos del estado de Puebla. Puebla, Universidad Iberoamericana, 1997.

Gastellou Josué, y Mauleón, Gustavo: Catálogo de órganos tubulares históricos del estado de Tlaxcala. Puebla, Universidad Iberoamericana, Gobierno del Estado de Tlaxcala, 1999.

Gembero-Uztárroz, María: “Muy amigo de música: el obispo Juan de Palafox (1600-1659) y su entorno musical en el Virreinato de Nueva España”, en Gustavo Mauleón Rodríguez (coord.), Juan Gutiérrez de Padilla y la época palafoxiana. Puebla, Gobierno del Estado de Puebla, Arzobispado de Puebla, 2010, pp. 55-130.

Gerhard, Peter: Geografía Histórica de la Nueva España 1519-1821. México, UNAM, 1986 [1972].

Gómez García, Lidia Ernestina, y Mauleón, Gustavo: “Un acercamiento a las capillas musicales en los pueblos indios del obispado de Puebla-Tlaxcala, siglos XVIXVIII", en Sergio Navarrete Pellicer (coord.), Ritual sonoro en catedral y parroquias. México, Ciesas, 2013, pp. 172-201.

Mauleón Rodríguez, Gustavo: "Noticias acerca de la etapa poblana del organista y compositor José María Carrasco $(* 1781 ; \dagger 1854) "$, IV Coloquio de Conservación de Órganos Tubulares. México, INAH/CNCPC-ENCRYM, 2016 [Ponencia inédita].

Mazín, Oscar: "Clero secular y orden social en la Nueva España de los siglos XVI y XVII", en Oscar Mazín et al., La secularización de las doctrinas de indios en la Nueva España. La pugna entre dos iglesias. México, UNAM / IISUE, 2010, pp. 139-211.

Menegus, Margarita: "La iglesia de los indios", en Oscar Mazín et al., La secularización de las doctrinas de indios en la Nueva España. La pugna entre dos iglesias. México, UNAM / IISUE, 2010, pp. 77-137.

Morales, Francisco: "Secularización de doctrinas. ¿Fin de un modelo evangelizador en la Nueva España?", en Actas del IV Congreso internacional sobre los franciscanos en el Nuevo Mundo (siglo XVIII). Madrid, Deimos, 1993, pp. 465-495.

Morales, Francisco: "La Iglesia de los frailes", en Oscar Mazín et al., La secularización de las doctrinas de indios en la Nueva España. La pugna entre dos iglesias, México, UNAM / IISUE, 2010, pp. 13-75.

Palafox y Mendoza, Juan de: Edictos del Ilustrísimo y Reverendísimo Señor don Juan de Palafox y Mendoza, 
obispo de la Puebla de los Ángeles. De la división y forma de las cordilleras y prefecturas del obispado para enviar y recibir las cartas y despachos de oficio por las secretarías de gobierno y de justicia. Y de los ornamentos y vasos sagrados, y las demás alhajas y instrumentos que son necesarios para las parroquias y lucimiento del Culto Divino. Puebla, Por el bachiller Juan Blanco de Alcázar, 1646.

Palafox y Mendoza, Juan de: Relación de las visitas eclesiásticas de parte del obispado de la Puebla de los Ángeles (1643-1646). Bernardo García Martínez (ed.). México, El Colegio de México, 2014 [1997].

Pareyón, Gabriel: "Carrasco (González), José María", en Diccionario enciclopédico de música en México. Guadalajara, Universidad Panamericana, 2006, tomo I, p. 189.

Pepe, Edward Charles: "Writing a history of Mexico's early organs: a seventeenth-century disposition from the Mexico City cathedral", en T. Donahue (coord.), Music and its questions. Essays in honor of Peter Williams. Richmond, Virginia, OHS Press, 2007a, pp. 49-74.
Pepe, Edward Charles: "Pipe Organs in Viceregal Mexico (1530-1820): Shifting Significations, Functions and Styles", en Colloquium: Music, Worship, Arts 4, Otoño, 2007b, pp. 15-29.

Pérez Puente, Luis: El concierto imposible. Los concilios provinciales en la disputa por las parroquias indígenas (México, 1555-1647). México, UNAM / IISUE, 2010.

Piho, Virve: "La secularización de las parroquias y la economía eclesiástica en la Nueva España”, en Journal de la Société de Américanistes 64, 1977, 81-88.

Piho, Virve: La secularización de las parroquias en la Nueva España y su repercusión en San Andrés Calpan. México, INAH, 1981.

Rubial, Antonio: "La mitra y la cogulla. La secularización palafoxiana y su impacto en el siglo XVII", en Relaciones. Estudios de Historia y Sociedad, 19 (73), invierno, 1998, pp. 239-272.

Voces del Arte. Inventario de órganos tubulares. México, SEDUE, 1989.

Recibido: 12.06 .2017

Aceptado: 27.07.2017 